US Army Corps

of Engineers $s_{\circledast}$

Engineer Research and

Development Center

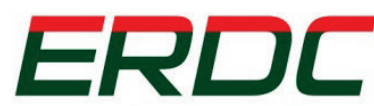

INNOVATIVE SOLUTIONS

for a safer, better world

Coastal Field Data Collection Program

\title{
Nearshore Survey System Evaluation
}

Michael F. Forte, William A. Birkemeier, and J. Robert Mitchell

December 2017

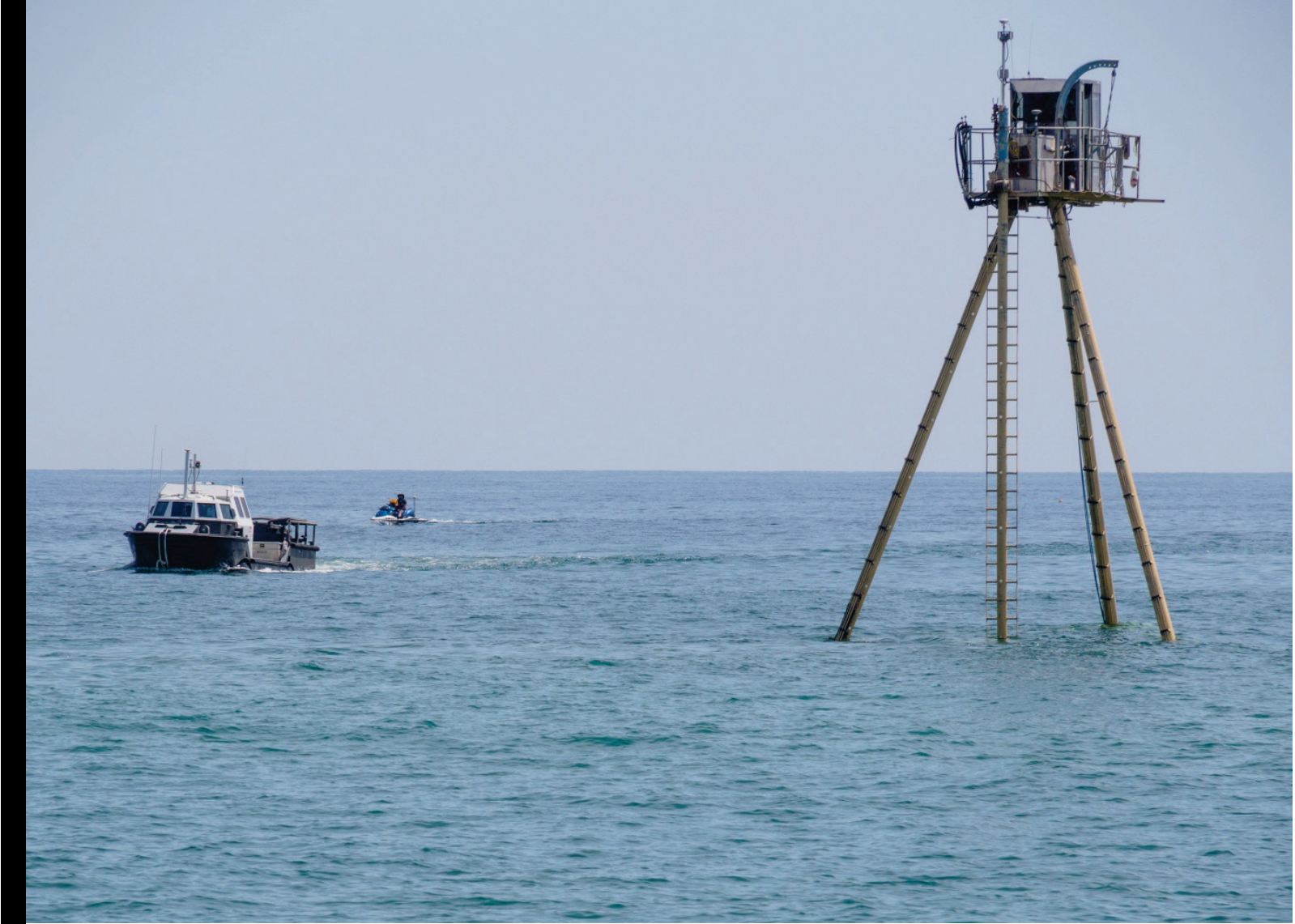


The U.S. Army Engineer Research and Development Center (ERDC) solves the nation's toughest engineering and environmental challenges. ERDC develops innovative solutions in civil and military engineering, geospatial sciences, water resources, and environmental sciences for the Army, the Department of Defense, civilian agencies, and our nation's public good. Find out more at www.erdc.usace.army.mil.

To search for other technical reports published by ERDC, visit the ERDC online library at http://acwc.sdp.sirsi.net/client/default. 


\section{Nearshore Survey System Evaluation}

Michael F. Forte, William A. Birkemeier, and J. Robert Mitchell

Field Research Facility

U.S. Army Engineer Research and Development Center

1261 Duck Road

Kitty Hawk, NC 27949

Final report

Approved for public release; distribution is unlimited.

Prepared for U.S. Army Corps of Engineers

Washington, DC 20314-1000

Under Coastal Field Data Collection Program No. 462585 


\section{Abstract}

This report evaluates the accuracy of two systems for surveying the beach and nearshore zone. The 10-meter (m)-tall Coastal Research Amphibious Buggy (CRAB) and the $10 \mathrm{~m}$ long Lighter Amphibious Resupply Cargo (LARC). The accuracy of the CRAB, in operation since 1981, to do centimeter-level surveys is well established. The main objective of this evaluation was to determine how well data collected with the LARC, under ideal survey conditions, compared to the CRAB. The field test consisted of repetitively surveying two profile lines (777 and 823): four times by the CRAB, nine times by the LARC. An all terrain vehicle (ATV) was used to survey the subaerial beach. The CRAB and ATV data were averaged to define a reference profile shape for use in determining the accuracy of the LARC surveys.

The two systems were found to compare extremely well with a mean difference of $\sim 1$ centimeter $(\mathrm{cm})$, well within measurement accuracy. The two systems compare best on the mildly sloping, shore-parallel shoreface, seaward of the nearshore sandbar where the two measuring systems differ least. The root mean square error between the LARC measurements and the $\mathrm{CRAB}$ mean profile was $2.2 \mathrm{~cm}$.

DISCLAIMER: The contents of this report are not to be used for advertising, publication, or promotional purposes. Citation of trade names does not constitute an official endorsement or approval of the use of such commercial products. All product names and trademarks cited are the property of their respective owners. The findings of this report are not to be construed as an official Department of the Army position unless so designated by other authorized documents.

DESTROY THIS REPORT WHEN NO LONGER NEEDED. DO NOT RETURN IT TO THE ORIGINATOR. 


\section{Contents}

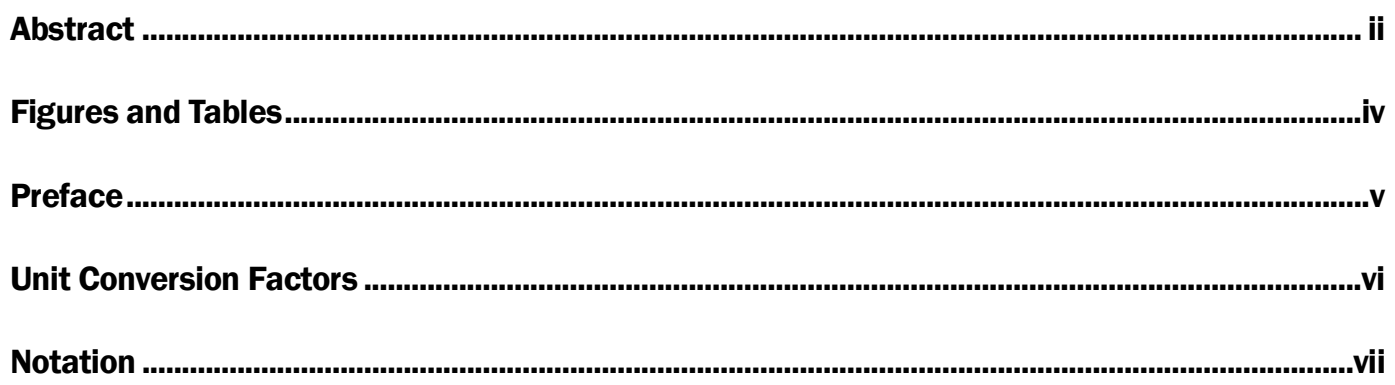

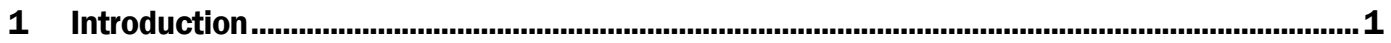

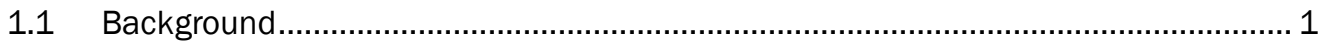

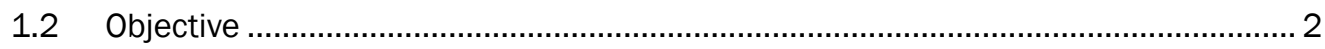

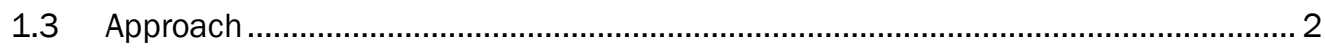

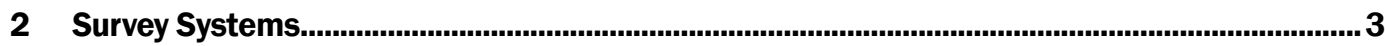

2.1 Trimble real-time kinematic Global Positioning System (RTK-GPS) System .............. 3

2.2 The Coastal Research Amphibious Buggy (CRAB) ............................................ 3

2.3 The Lighter Amphibious Resupply Cargo (LARC) ............................................... 6

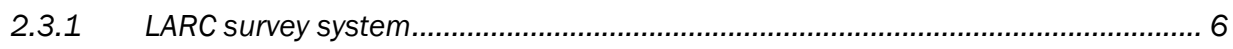

2.3.2 LARC survey data analysis with Fathomax ........................................................ 8

2.4 All terrain vehicle (ATV) beach survey.......................................................... 11

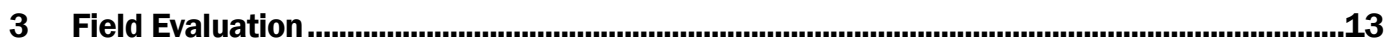

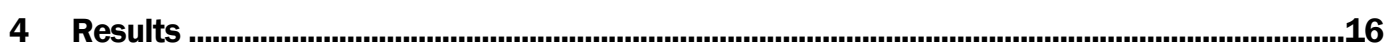

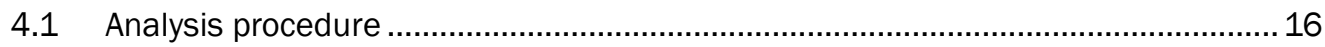

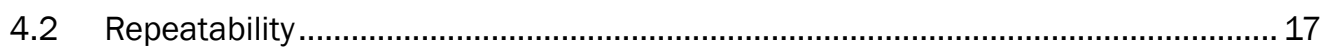

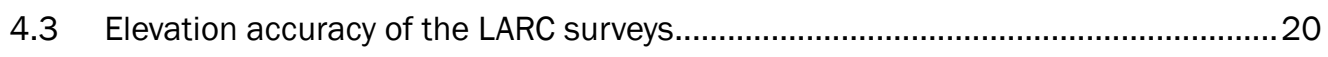

4.4 Beach survey compared to the ATV .................................................................. 24

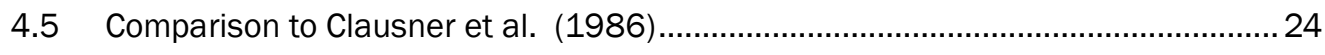

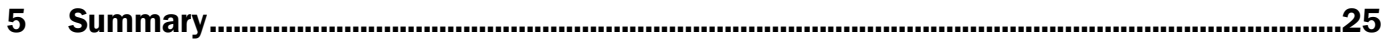

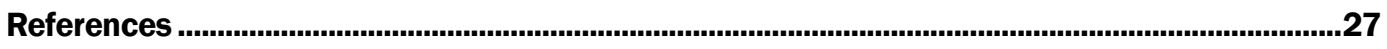

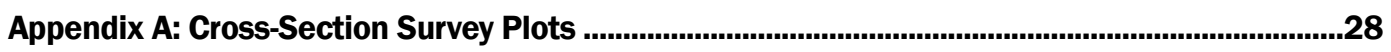

Report Documentation Page 


\section{Figures and Tables}

\section{Figures}

Figure 1-1. The LARC (left) and CRAB (right).

Figure 2-1. The CRAB during the evaluation test. Note how it tilts on the steep part of the beach at the base of the dune.

Figure 2-2 . GPS Antenna mounted on the top of the pole on the back of the CRAB......................... 5

Figure 2-3. Example GPS and echosounder data from cross-shore transect 777_1347.................... 9

Figure 2-4. The effect on depth of varying latency between GPS and echosounder values. ............10

Figure 2-5. Final cross section computed by Fathomax for the raw data in Figure 2-3.

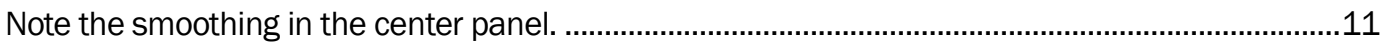

Figure 2-6. The ATV with RTK-GPS used to survey the subaerial beach...........................................12

Figure 3-1. The CRAB and LARC surveying offshore, 11 July 2016...............................................13

Figure 3-2. Collected CTD profiles.

Figure 4-1. Cross-section plots of profile line 823. CRAB-IMU surveys are shown in the left panels; LARC-RAW data are shown in the right panels. Colors represent the different survey repetitions.

Figure 4-2. Variation in the standard deviation of elevation for all survey repetitions for profile line 823.

Figure 4-3. The reference profile for the CRAB-IMU surveys of 823 . Colors represent different repetitions used in computing the mean profile.

Figure 4-4. Profile line 823 surveys relative to the mean profile. Colors represent different LARC survey repetitions.

Figure 4-5. Comparison between the LARC-raw elevation data and the reference profile for Profile Lines 777 (left panel) and 823 (right panel).

Figure A-1. Plot of the four repetitions of the CRAB-IMU data on profile line 777.

Figure A-2. Plot of the four repetitions of the CRAB-IMU half-median data on profile line 777............29

Figure A-3. Plot of the nine repetitions of the LARC-raw data on profile line 777..............................30

Figure A-4. The nine repetitions of the LARC half-median+3 pt smooth data on profile line 777.............31

Figure A-5. The nine repetitions of the CRAB-IMU data on profile line 823.....................................32

Figure A-6. The four repetitions of the CRAB-IMU half-median data on profile line 823....................33

Figure A-7. The nine repetitions of the LARC-raw data on profile line 823........................................34

Figure A-8. The nine repetitions of the LARC half-median +3-point smooth data on profile line 823.

\section{Tables}

Table 3-1. Summary of CRAB surveys. ......................................................................................

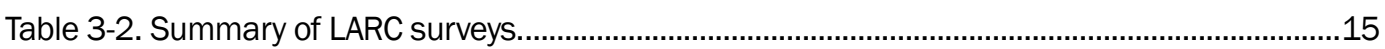

Table 4-1. Online/Offline statistics for the CRAB and LARC surveys by zones. ................................18

Table 4-2. Vertical variation statistics for the CRAB and LARC surveys by zones...............................19 


\section{Preface}

This study was conducted for the U.S. Army Corps of Engineers under the Coastal Field Data Collection Program. The technical monitor was Dr. Jeffrey P. Waters.

The work was performed by the Coastal Observations and Analysis Branch (CEERD-HFA) of the Flood and Storm Protection Division (CEERD-HF), U.S. Army Engineer Research and Development Center, Coastal and Hydraulics Laboratory (ERDC-CHL). At the time of publication, Dr. Jeffrey P. Waters was Chief, Coastal Observation and Analysis Branch (CEERD-HF-A); Dr. Cary A. Talbot was Chief, Flood and Storm Protection Division (CEERD-HF); and Dr. Julie D. Rosati was the Technical Director for the Flood Risk Management Program. The Deputy Director of ERDCCHL was Mr. Jeffrey R. Eckstein, and the Director was Mr. José E. Sánchez.

Appreciation is extended to the operations team at the Field Research Facility, including Mr. Jason Pipes, Mr. Brian Scarborough, and Mr. Mark Preisser who helped make this field test a success.

COL Bryan S. Green was Commander of ERDC, and Dr. David W. Pittman was the Director. 


\section{Unit Conversion Factors}

\begin{tabular}{|l|c|l|}
\hline Multiply & By & To Obtain \\
\hline Feet & 0.3048 & Meters \\
\hline Meters & 3.2808398950131 & Feet \\
\hline Meters & 3.2808334366796 & Survey Feet \\
\hline Survey feet & 0.3048006 & Meters \\
\hline
\end{tabular}




\section{Notation}

ATV

CEERD-HF

CEERD-HF-A

CHL

CORS

CRAB

CTD

ERDC

ERDC-CHL

FRF

$\mathrm{ft}$

GPS

HYPACK

IMU

INS

$\mathrm{kg}$

$\mathrm{km}$

LARC

LARC-V

$\mathrm{m}$ all-terrain vehicle

U.S. Army Corps of Engineers, Engineer Research and Development Center, Flood and Storm Protection Division

U.S. Army Corps of Engineers, Engineer Research and Development Center, Flood and Storm Protection Division, Coastal Observations and Analysis Branch Coastal and Hydraulics Laboratory, one of the laboratories of ERDC

Continuously Operating Reference Station. CORS is a NOAA National Geodetic Survey NGS program of continuously operating GPS stations.

Coastal Research Amphibious Buggy

conductivity, temperature, and depth observation

U.S. Army Engineer Research and Development Center

U.S. Army Engineer Research and Development Center, Coastal and Hydraulics Laboratory

Field Research Facility

foot/feet

Global Positioning System

A Hydrographic Package of software for collecting hydrographic survey data available from HYPACK, Inc.

inertial measurement unit

inertial navigation system

kilogram(s)

kilometer(s)

Lighter Amphibious Resupply Cargo

Lighter Amphibious Resupply Cargo V

meter(s) 


$\begin{array}{ll}\text { NOAA } & \text { National Oceanic and Atmospheric Administration } \\ \text { PDOP } & \text { position dilution of precision } \\ \text { RMS } & \text { root mean square } \\ \text { RTK-GPS } & \text { Real-Time Kinematic Global Positioning System } \\ \text { TSS } & \text { Teledyne TSS } \\ \text { USACE } & \text { U.S. Army Corps of Engineers } \\ \text { UTC } & \text { Coordinated Universal Time }\end{array}$




\section{Introduction}

\subsection{Background}

The Field Research Facility (FRF) is a coastal observatory established in 1977 and located on the Atlantic Ocean near Duck, NC. The facility is operated by the Coastal Observations and Analysis Branch of the Coastal and Hydraulics Laboratory (CHL), one of the laboratories of the U.S. Army Engineer Research and Development Center (ERDC), Vicksburg, MS. One of the missions of CHL is to collect concurrent coastal process and response data to improve the understanding of and ability to model nearshore dynamics. Process data include waves, tides, and currents along with local weather; response data include topographic and bathymetric surveys.

The surveys consist of repetitively mapping a series of cross-shore profile lines. Surveys are conducted using the 10-meter (m) tall Coastal Research Amphibious Buggy (CRAB) and the $10 \mathrm{~m}$ long Lighter Amphibious Resupply Cargo (LARC), both uniquely capable for nearshore surveying (Figure 1-1). Surveys using the CRAB began in January 1981. Several different surveying methods have been used with the most recent system being a real-time kinematic Global Positioning System (RTK-GPS).

Figure 1-1. The LARC (left) and CRAB (right).
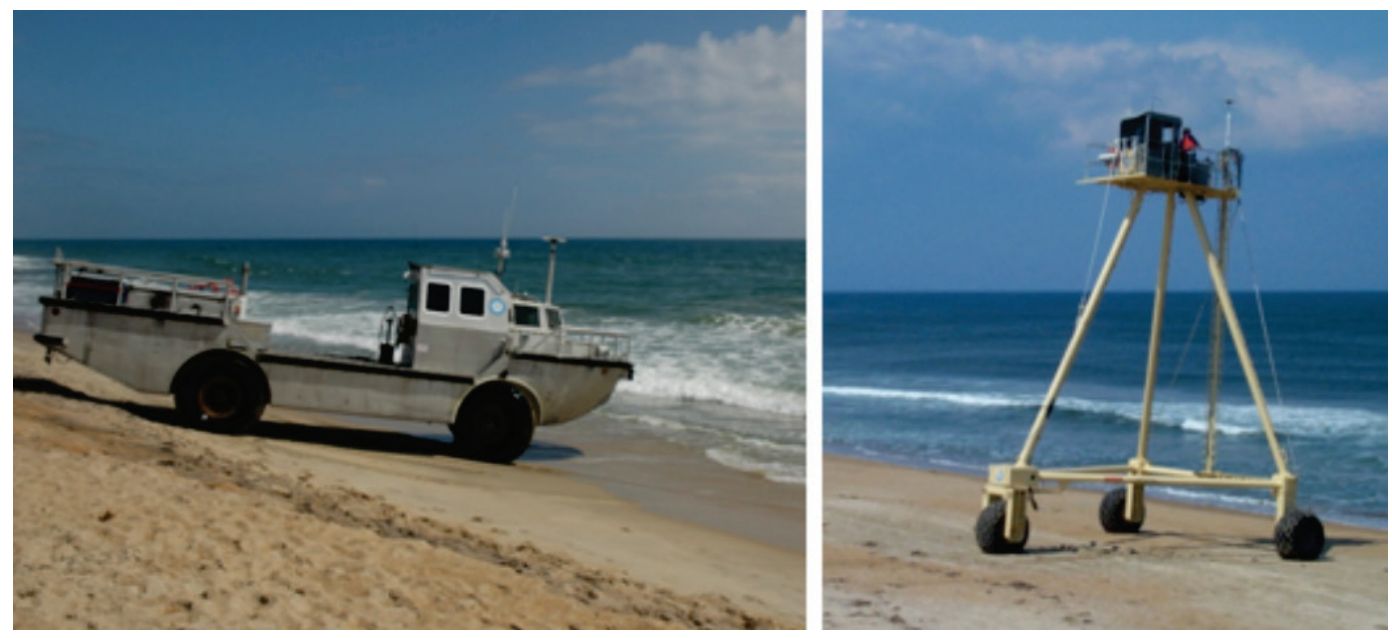

Because the surveys are used to quantify small changes in the nearshore profile, vertical accuracy has always been a concern and a major reason for using the CRAB, which allows an accurate land-based topographic survey 
to be carried offshore. The accuracy of the each of the survey methods used with the CRAB was established through repetitive surveys of the same profile line as described in Howd and Birkemeier (1987), Lee and Birkemeier (1993), and Clausner et al. (1986). Clausner et al. (1986) also reported that because of wave motion, use of an echosounder and boat, though faster than the CRAB, did not meet the desired accuracy requirements at that time. That changed with the advent of RTK-GPS, which can be used to remove the influence of waves and tide from the echosounder signal. The first use of RTK-GPS was on the CRAB in 1996, and it was deployed on the LARC in 1999. Though the RTK-GPS/LARC system was evaluated internally for accuracy and compared extensively to the $\mathrm{CRAB}$, a comprehensive evaluation had not been done or published.

\subsection{Objective}

The purpose of this paper is to report on the results of a survey evaluation of the LARC and CRAB using RTK-GPS conducted at the Field Research Facility in July 2016.

\subsection{Approach}

The field test consisted of repetitively surveying two profile lines (777 and 823): four times by the CRAB, nine times by the LARC. An all terrain vehicle (ATV) was used to survey the subaerial beach. The CRAB and ATV data were averaged to define a reference profile shape for use in determining the accuracy of the LARC surveys.

The report is organized into 4 chapters. Chapter 2 describes the CRAB and LARC survey systems. Chapter 3 discusses the field evaluation test and Chapter 4 discusses the results. Appendix A provides plots of the survey data collected. 


\section{Survey Systems}

This Chapter describes the different survey systems and their operation in detail.

\subsection{Trimble real-time kinematic Global Positioning System (RTK- GPS) System}

Both the CRAB and the LARC were equipped with Trimble Model 5700 dual frequency RTK-GPS systems configured as rovers sampling at 1 hertz $(\mathrm{Hz})$. The base station is located within 2 kilometers $(\mathrm{km})$ and is associated with the National Oceanic and Atmospheric Administrationoperated Continuously Operated Reference Station (CORS) NCDU. The base station uses a Trimble Model 5700 connected to the CORS antenna. The base station computes its location using signals from five to nine satellites and then computes position corrections by comparing each reading to the known station coordinates. The corrections are sent via radio transmission in real time to the rover receivers. The GPS sampling rate is set at $1 \mathrm{~Hz}$, the basic sample rate of the RTK-GPS system.

Under ideal satellite and atmospheric conditions, the horizontal accuracy of an RTK position is \pm 1 centimeter $(\mathrm{cm}) \pm 1$ part per million (ppm) based on the distance to the base station. Vertical accuracy is $\pm 2 \mathrm{~cm} \pm 2 \mathrm{ppm}$ Trimble (2003). Since the maximum distance to the base station during the testing was $\sim 800 \mathrm{~m}$, the vertical accuracy of the GPS positions was $\pm 2.15 \mathrm{~cm}$.

\subsection{The Coastal Research Amphibious Buggy (CRAB)}

The CRAB (Figure 2-1) is described in Birkemeier and Mason (1984). Built by the Wilmington District of the U.S. Army Corps of Engineers USACE), this unique three-wheeled vehicle was modeled after a vehicle originally built by Marine Travelift and Engineering of Sturgeon Bay to monitor beach nourishment projects. 
Figure 2-1. The CRAB during the evaluation test. Note how it tilts on the steep part of the beach at the base of the dune.

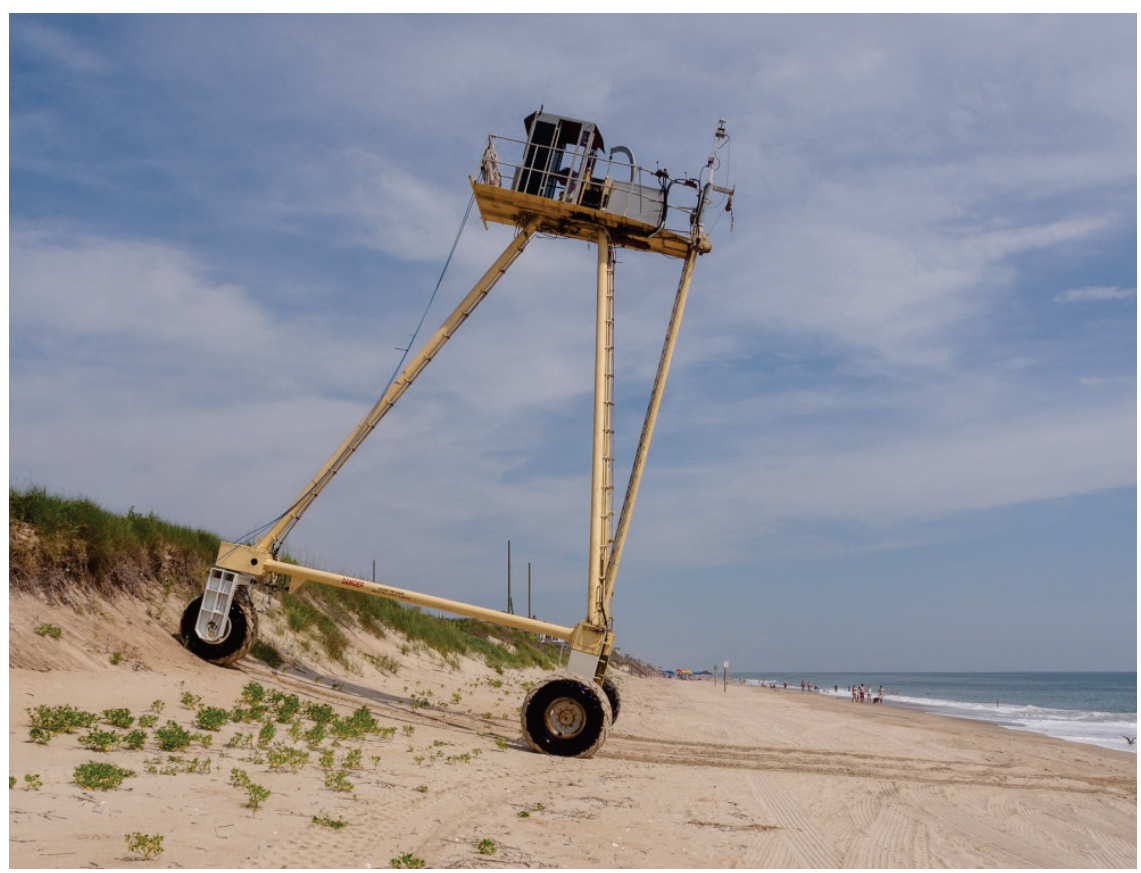

The CRAB consists of a tripod of $20.3 \mathrm{~cm}$, schedule 80 aluminum tubing, connected at the base by horizontal members $2.1 \mathrm{~m}$ above the ground, with an operations platform $10.7 \mathrm{~m}$ above the ground. It is $7.6 \mathrm{~m}$ between the center of the rear wheels and $8.3 \mathrm{~m}$ from the front wheel to the rear axle. Power is supplied by an 82 horsepower V380o-DI-T turbo diesel Kubota engine on the deck that drives a variable-stroke hydraulic pump. This pump transfers hydraulic fluid at $5.5 \times 106$ newtons $(\mathrm{N}) / \mathrm{m}^{2}$ or higher to hydraulic motors at each of the wheels. The variable-stroke feature of the pump allows an infinitely variable gear ratio in either forward or reverse and constant engine speed. For strength and corrosion resistance, all hydraulic lines are stainless steel except for short flexible sections at the front steerable wheel. Total vehicle weight is approximately 8,200 kilograms. Although it appears top heavy, the liquid-filled tires and wide wheelbase make it very stable. It has passed a 20-degree (deg) tilt test and is designed to withstand even steeper angles.

Top speed of the CRAB is $3.2 \mathrm{~km} /$ hour (hr) on land and somewhat less in the water. The maximum significant wave height considered for safe operation is $\sim 1.5 \mathrm{~m}$, based primarily on rescue concerns if it were to break down under higher waves. On a few occasions, the CRAB has been operated under higher waves ( $>2 \mathrm{~m}$ ), and the operator felt one of the wheels being briefly lifted off the bottom. 
The CRAB does make tracks on the beach, and tracks offshore have been observed in a side-scan record, but close inspection by divers indicate that the large tires have a negligible effect on a hard, rippled sand bottom. No adjustment is made for any sinking in the sand. Scour around the tires has been observed in areas of active wave breaking or strong currents if the CRAB remains motionless. The CRAB cannot be used on soft, silty, or steeply sloped bottoms.

When the CRAB is used for surveys, its height allows highly accurate topographic surveys techniques to extend offshore to a depth of $\sim 9 \mathrm{~m}$. Since the GPS antenna is mounted directly above and centered over the back two wheels, it averages the elevation between the rear wheels (Figure 2-2).

Figure 2-2. GPS Antenna mounted on the top of the pole on the back of the CRAB.

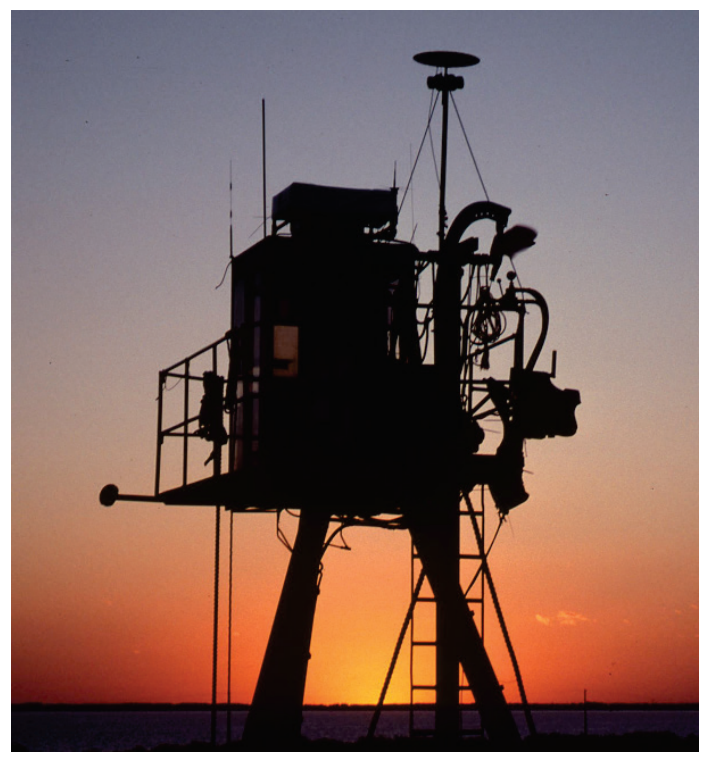

The most critical measurement to collecting accurate data with the CRAB is knowing the height of the GPS antenna above the ground. This is done by checking the elevation of a specific parking lot point during each day of surveying. During the survey test, the GPS antenna phase center to ground was measured with a plumb bob and recorded as $13.423 \mathrm{~m}$.

During a survey the CRAB tilts, particularly on the steep slopes of the subaerial beach. Because of its height, this can significantly affect the measured ground elevation. Tilt during the test was measured two ways: (1) using an inertial navigation system (INS) to measure pitch and roll 
angles and (2) using the Slope-Tilt technique where the observed slope of the beach from the GPS measurements is used to first estimate and then correct for the tilt.

The HYPACK Inc. HYPACK hydrographic survey software was used to log the data stream from the GPS and INS and to provide steering information to the CRAB driver. Fathomax, a custom FORTRAN program developed at the FRF, was used to process the collected data. Fathomax computed the elevation of the CRAB by subtracting the height of the GPS antenna from the GPS elevation data, accounted for the tilt of the CRAB using both the Slope-Tilt technique and by applying the pitch and roll angles measured from the INS. Fathomax then converted the observed geodetic coordinates to the local FRF coordinate system.

The CRAB equipment consists of the following:

- RTK-GPS using Trimble 5700 dual-frequency receiver configured for 1-second (sec) updates

- Novatel SPAN-CPT Inertial Navigation System

- Data Collection-Tangent computer.

\subsection{The Lighter Amphibious Resupply Cargo (LARC)}

While the CRAB with RTK-GPS is a robust and accurate survey system, it is slow, depth limited, not transportable, and requires a hard, mildly sloping bottom. These limitations are addressed with the LARC equipped with RTK-GPS, a digital echosounder, and a heave-pitch-roll sensor.

\subsubsection{LARC survey system}

The LARC 5 ton, or LARC-V, is the smallest of a class of amphibious vessels developed and operated by the Army in the 1950s and used in the Korean and Vietnam Wars. It is $10.7 \mathrm{~m}$ long, diesel powered, with 4-wheel drive, and capable of speeds of 8 knots in water $(15 \mathrm{~km} / \mathrm{hr})$ and $26 \mathrm{knots}$ $(48 \mathrm{~km} / \mathrm{hr})$ on land. Though long out of production, they are still in use today. LARCs are known for their seaworthiness, particularly in breaking waves. To facilitate surveying, the FRF LARC is equipped with a 220/110volt diesel generator, expanded cabin space, and air conditioning. The cabin provides counter space for the computers and allows the pilot and surveyor to be in close contact during a survey. 
In operation, the pilot steers the LARC over a pre-defined course of profile lines at a speed of approximately $7 \mathrm{~km} / \mathrm{hr}$ ( 4 knots). As on the CRAB, the HYPACK navigation system provides real-time position information to computer monitors in the LARC cab, which enables the pilot to accurately steer the line. Topographic points are determined by using the height of the GPS antenna above the ground. Once the LARC is floating, the echosounder is used. Since echosounder data are affected by density changes in the water column, the speed of sound is collected, either from the LARC periodically during the day or from the end of the FRF pier. While the LARC can operate under higher wave conditions, air entrainment in the surf zone limits surveying to conditions with waves generally less than $1 \mathrm{~m}$.

The LARC equipment consists of the following:

- RTK-GPS using Trimble 5700 dual-frequency receiver configured for 1-sec updates

- Knudsen MiniSounder with 200 kilohertz (kHz) transducer KEL8355 deg beam

- Data collection - Tangent computer

- Teledyne TSS DMS 3-25 motion sensor for heave, pitch and roll

- Teledyne Odom Digibar Pro - for measuring speed of sound in water.

Because depth readings are needed as soon as the LARC enters the water and starts to float, the echosounder allows depth measurement as shallow as $15 \mathrm{~cm}$. The 5 deg beam width of the Knudsen $200 \mathrm{kHz}$ transducer equates to a bottom measuring patch $0.34 \mathrm{~m}$ diameter at $4 \mathrm{~m}$ depth and $0.69 \mathrm{~m}$ at $8 \mathrm{~m}$ depth. This is a much smaller measuring patch than the $\mathrm{CRAB}$, which averages across its $7.6 \mathrm{~m}$ rear axle. The transducer is mounted between the front wheels of the LARC directly below the GPS antenna. This location minimizes the bubbles that form and pass under the LARC as it transits breaking waves in the surf zone. However, in this location, the transducer may come out of the water as the LARC travels offshore through breaking waves. When this happens, it creates a data gap in the observed water depths. When traveling towards shore and with the waves, the transducer remains in the water providing more complete coverage. The manufacturer's published accuracy of the echosounder is $\pm 1 \mathrm{~cm}, \pm 0.1 \%$ of the depth value. Since measured depths during the test were less than $8 \mathrm{~m}$, the stated accuracy equals $\pm 1.8 \mathrm{~cm}$. Since the error 
increases with depth, at the typical offshore survey depth of $15 \mathrm{~m}$, the depth accuracy decreases to $\pm 2.5 \mathrm{~cm}$.

The $320 B P$ Echosounder is sampled at a rate of $10 \mathrm{~Hz}$. This high sample rate is important because it permits the analysis software to first apply a robust median-based filter to the echosounder data before determining the water depth at the exact moment that the $1 \mathrm{~Hz}$ RTK-GPS data are acquired.

Knowing the RTK-GPS and echosounder accuracy, and assuming that the errors are independent and additive, then a vertical error budget for the system can be computed using the following equation:

$$
\Delta Z=\sqrt{(\Delta \text { Echosounder })^{2}+(\triangle G P S)^{2}}
$$

With the errors for the GPS and echosounder as stated above, the following is presented: $\Delta$ GPS $= \pm 2.15 \mathrm{~cm} ; \Delta$ Echosounder $= \pm 1.8 \mathrm{~cm}$ gives a $\Delta \mathrm{Z}= \pm 2.8 \mathrm{om}$. This is the obtainable system accuracy, assuming random errors. It is different from systematic and offset errors (i.e., sound speed errors, base station errors, antenna height errors) that can significantly affect overall data accuracy.

\subsubsection{LARC survey data analysis with Fathomax}

The LARC depth is observed relative to a rolling platform and is computed by combining the RTK-GPS, echosounder, and motion sensor data streams. This is also done using Fathomax, which performs these operations:

- separates and cleans the RTK-GPS and echosounder data streams

- adjusts echosounder data for the speed of sound profile

- corrects the echosounder data for any drift of the data collection computer's clock

- separates topographic (over land) points from bathymetric (in water) points;

- interpolates an echosounder reading for each bathymetric RTK-GPS point

- optimizes the match between the RTK-GPS and echosounder data in time

- optionally smoothes the final elevation data

- creates an X, Y, Z output file. 
Figure 2-3 is an example of the collected raw data. The fathometer trace (red line, bottom panel) can be quite noisy with frequent dropouts, particularly in the shallowest region where the sandbar occurs. Fathomax uses several routines to filter through the dropouts and adjusts the data for the speed of sound producing a refined seafloor trace (black line, bottom panel).

Before the wave motion can be removed from the echosounder data, the echosounder data has to be precisely time stamped. The GPS data stream is stamped with both GPS clock time and the internal clock of the collection computer. However, the echosounder data are only stamped with the internal clock. Since internal personal computer clocks may drift (maximum observed $\sim 0.25 \mathrm{sec}$ in 10 minutes), the drift is computed by comparing the times on the GPS data. Once computed, the $t$ is removed from the echosounder data.

Figure 2-3. Example GPS and echosounder data from cross-shore transect 777_1347.

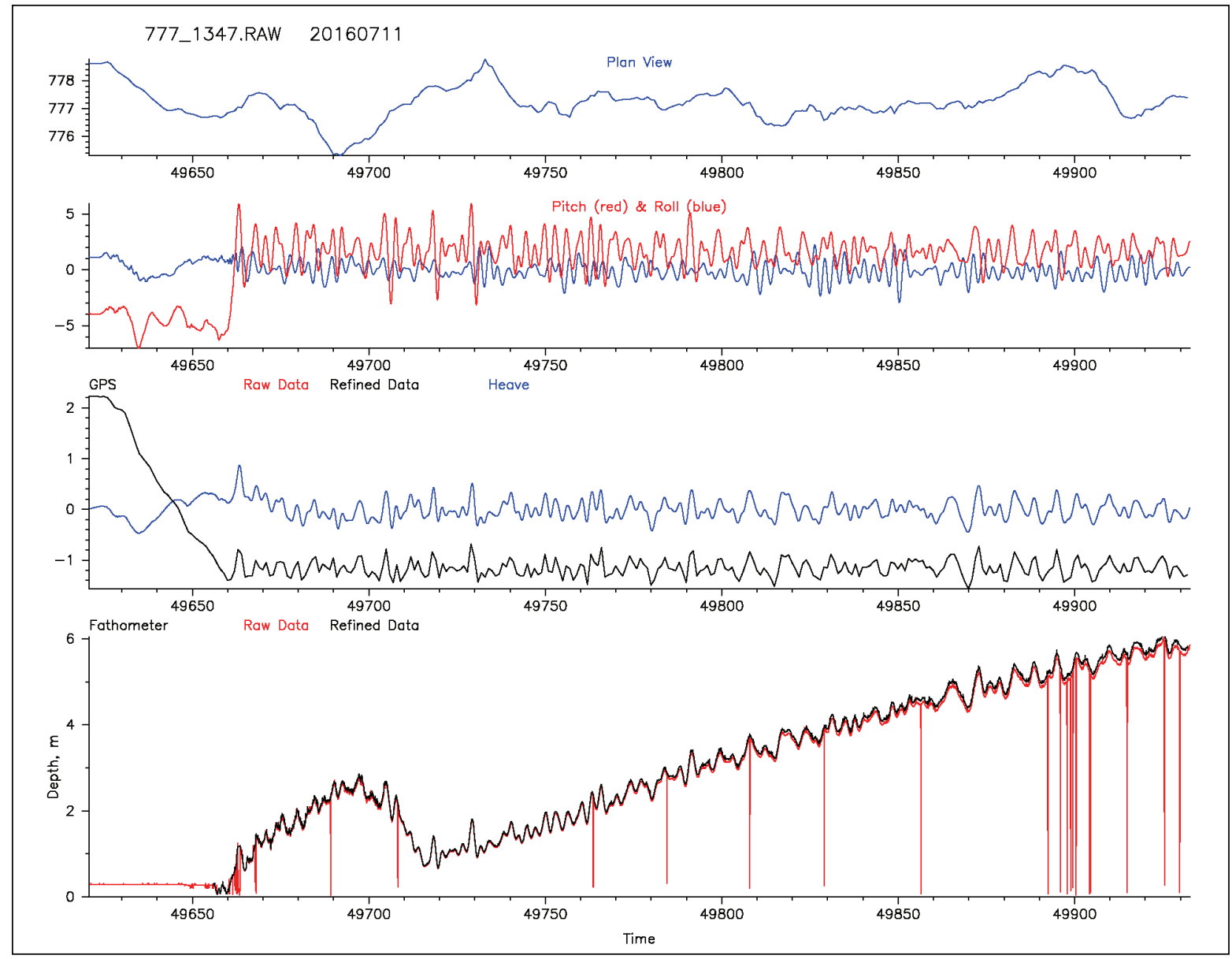


Land points are separated from over-water points by determining when the LARC is floating. This is done by first computing the mean and standard deviation of the GPS observations for points when the LARC was clearly floating (echosounder depths greater than $2 \mathrm{~m}$ ). The LARC is considered to be on land when the GPS observed elevation is greater than the mean overwater GPS elevation plus 3.9 times the over-water GPS standard deviation, Once over-water points are identified, the echosounder and GPS data are adjusted based on pitch and roll and then aligned in time to produce the smoothest seafloor profile. This is accomplished by iteratively adjusting the time (or latency) of the GPS data, relative to the echosounder data, until a best fit based on bottom smoothness is obtained. Evident in Figure 2-4, the computation of this latency is quite sensitive, with hundredths of a second having an impact. The green line with a latency of $1.36 \mathrm{sec}$ has the least remaining wave action and is the best fit. Figure 2-4 is from older equipment with a latency that was longer than the $1 \mathrm{~Hz}$ sample rate.

Figure 2-4. The effect on depth of varying latency between GPS and echosounder values.

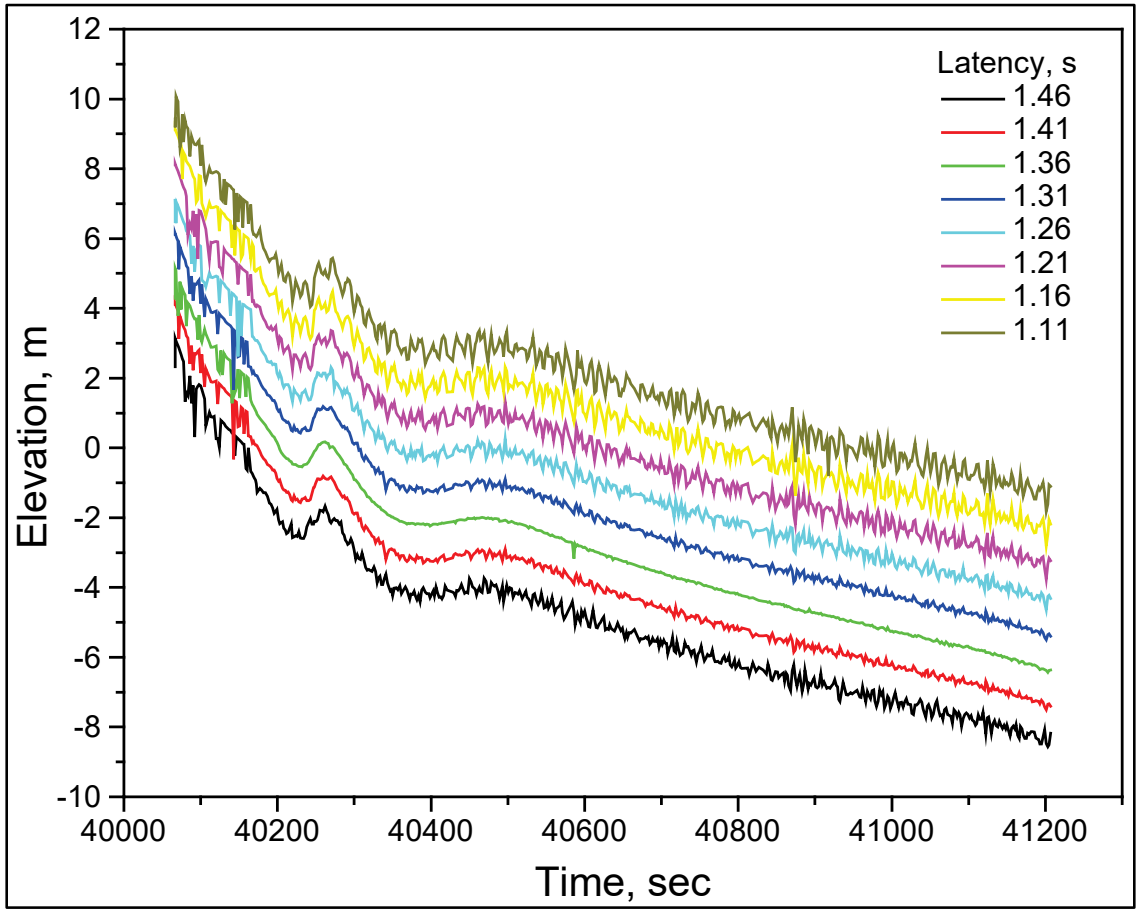

Because the latency is dependent on the timing between sensors, computers, and software, it would be expected to be a constant value. However, that is not the case, and a new latency value is computed for each survey line. With the equipment used during the test, latency was close to but never zero, varying from -0.05 to $0.07 \mathrm{sec}$. 
The resulting cross section for the data in Figure 2-3 is shown in Figure $2-5$. Since most but not all motion is removed, the final data are optionally smoothed with a median smooth, a moving average, or a combination of the two. Data filtering/smoothing is not applied to above-datum (beach) points and over regions with steep slopes or that lack data density.

Fathomax also preserves the original, raw version of the data. Additional hand editing is completed outside of Fathomax to remove any remaining offline points or spikes that survived the automatic checks.

Figure 2-5. Final cross section computed by Fathomax for the raw data in Figure 2-3. Note the smoothing in the center panel.

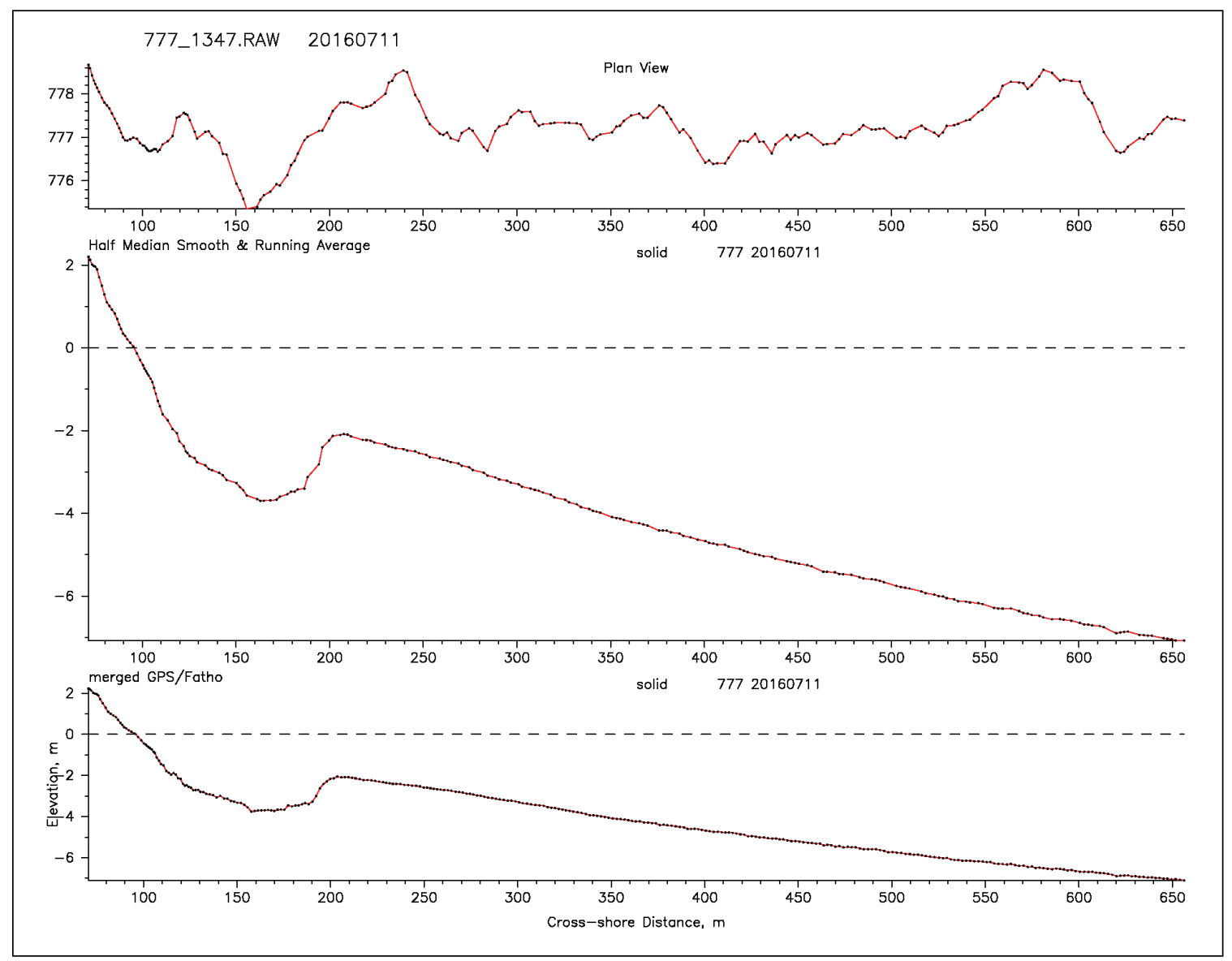

\subsection{All terrain vehicle (ATV) beach survey}

To compare the ability of the CRAB and the LARC to survey the beach, an ATV was also used to survey the beach (Figure 2-6). The ATV was equipped similarly to the CRAB with a Trimble RTK-GPS Model 5700, a GPS antenna on a short pole, and a tablet computer running the Hypack software. 
In operation, the ATV was driven from the base of the dune to the water's edge using the Hypack navigation screen to maintain position on the defined profile line. Two surveys were conducted and averaged for use in the comparisons.

Figure 2-6. The ATV with RTK-GPS used to survey the subaerial beach.

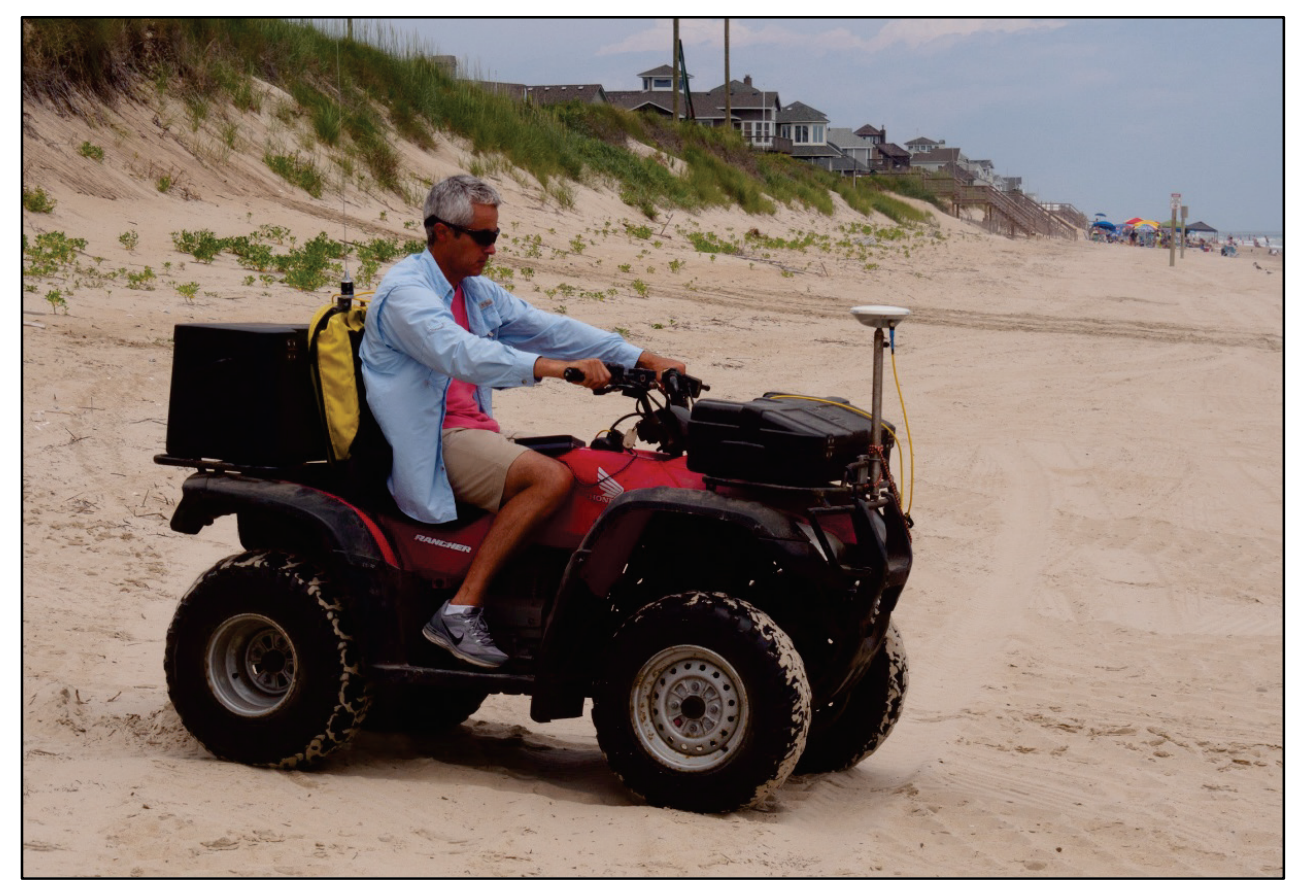




\section{Field Evaluation}

A field evaluation was conducted on 11 July 2016 between 1200 and 1700 Coordinated Universal Time (UTC). Two existing profile lines (777 and 823) $46 \mathrm{~m}$ apart were repetitively surveyed. Line 777 was surveyed driving offshore, and Line 823 was driven onshore. This was done to see if there were any bias in the data caused by the survey direction.

Figure 3-1. The CRAB and LARC surveying offshore, 11 July 2016.

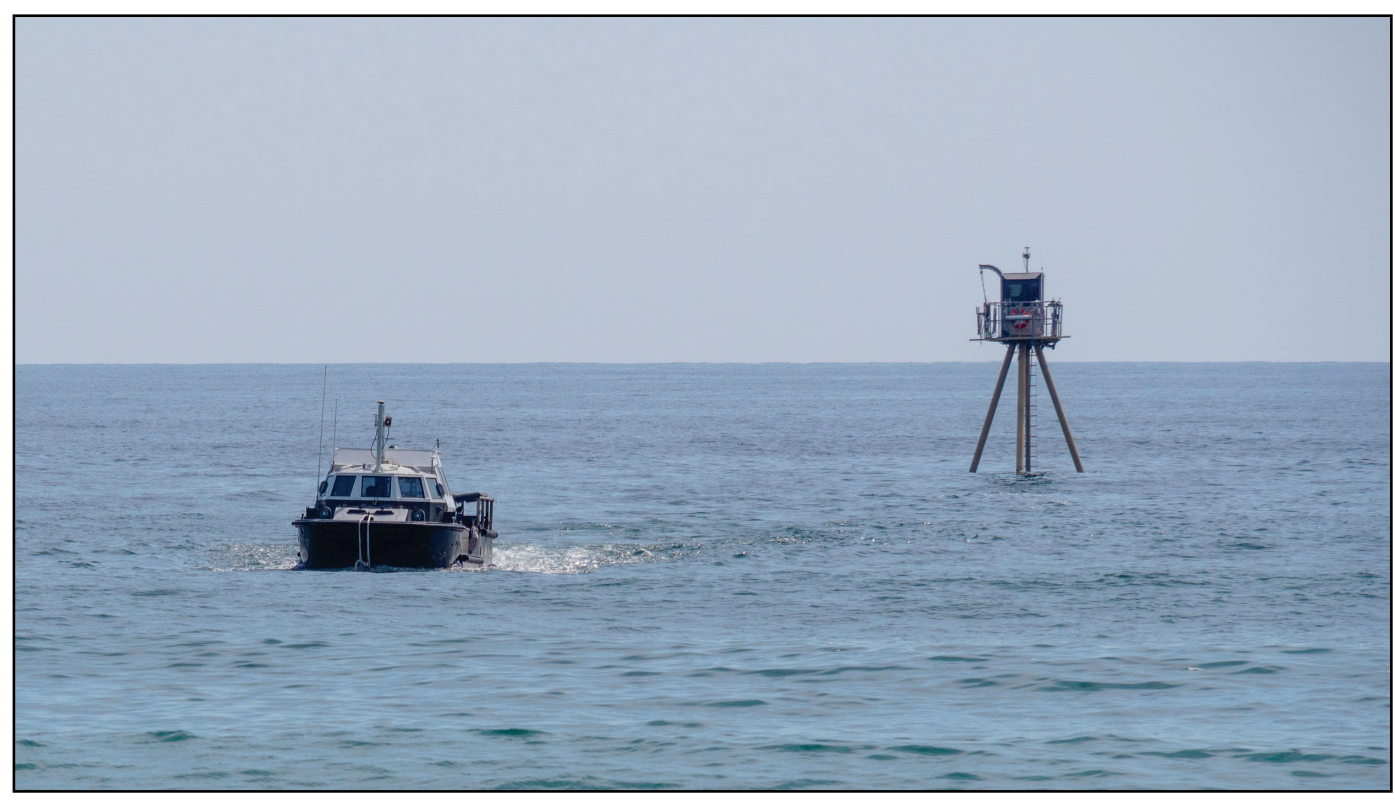

Evident in Figure 3-1, it was an ideal survey day. Wave conditions were a low, long-period swell (wave height $=0.54 \mathrm{~m}$, peak wave period $=8.3 \mathrm{~s}$, wave direction=93 deg True North).

To determine the speed of sound in water, four conductivity, temperature, depth (CTD) profiles were collected at the seaward end of the survey lines during the day. As shown in Figure 3-2, the sound speed profile changed from a stratified profile to a uniform profile later in the day. Using the CTD data, a depth-dependent multiplier is computed that is used to correct the echosounder depths. 
Figure 3-2. Collected CTD profiles.

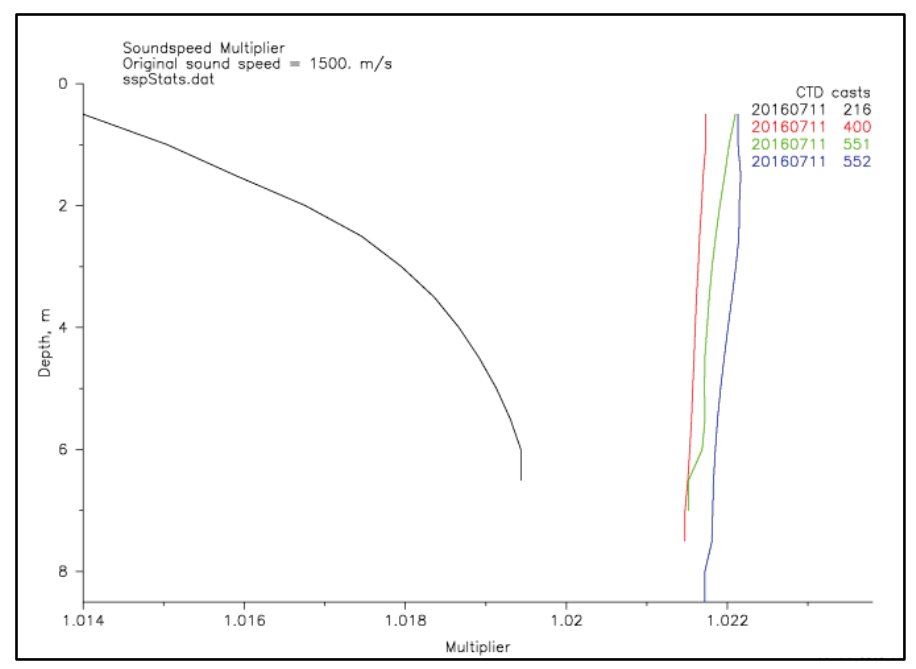

Table 3-1 lists the four surveys of each line done by the CRAB, and Table 3-2 summarizes the nine LARC surveys. Four CRAB surveys were collected for use in computing a mean, reference profile for comparison with the LARC data. The collected data were processed several ways using Fathomax to examine the impact of different filtering methods on the final result. For the LARC, two data versions were created: (1) LARC-raw, the original unfiltered data and (2) Half-median and smooth, which starts with the LARC-raw data and drops the largest outlier of every 3 points (half-median) and then does a 3-point moving average of the decimated result. This filtering is effective at removing any remnant wave noise in the bottom signal. The half-median removes outliers without affecting adjacent points while the running average smooths the data by influencing adjacent points.

Table 3-1. Summary of CRAB surveys.

\begin{tabular}{|c|c|c|c|c|c|c|c|c|c|c|c|}
\hline \multirow[b]{3}{*}{ Profile } & \multirow{2}{*}{\multicolumn{3}{|c|}{ Survey Number }} & \multirow[b]{3}{*}{ HYPACKfile } & \multirow[b]{3}{*}{$\begin{array}{l}\text { Elapsed } \\
\text { Time } \\
\text { (min) }\end{array}$} & \multirow[b]{3}{*}{$\begin{array}{l}\text { Speed } \\
(\mathrm{m} / \mathrm{s})\end{array}$} & \multicolumn{4}{|c|}{ Data Points } & \multirow[b]{3}{*}{ PDOP } \\
\hline & & & & & & & \multicolumn{2}{|c|}{ Original } & \multicolumn{2}{|c|}{ Half-median } & \\
\hline & $\begin{array}{l}\text { CRAB- } \\
\text { IMU }\end{array}$ & $\begin{array}{l}\text { CRAB } \\
\text { Half- } \\
\text { median }\end{array}$ & $\begin{array}{l}\text { CRAB } \\
\text { SlopeTilt }\end{array}$ & & & & Points & $\begin{array}{l}\text { Spacing } \\
(\mathrm{m})\end{array}$ & Points & $\begin{array}{l}\text { Spacing } \\
(\mathrm{m})\end{array}$ & \\
\hline 777 & 1 & 41 & 11 & 777 1323.RAW & 15.3 & 0.63 & 917 & 0.6 & 632 & 0.9 & 2.7 \\
\hline 777 & 2 & 42 & 12 & 777 1402.RAW & 14.1 & 0.67 & 849 & 0.7 & 589 & 1.0 & 2.3 \\
\hline 777 & 3 & 43 & 13 & 777 1459.RAW & 15.3 & 0.63 & 916 & 0.6 & 636 & 0.9 & 2.1 \\
\hline 777 & 4 & 44 & 14 & 777 1538.RAW & 17.0 & 0.57 & 1020 & 0.6 & 694 & 0.8 & 1.7 \\
\hline 823 & 1 & 41 & 11 & 823_1340.RAW & 15.0 & 0.65 & 898 & 0.6 & 610 & 1.0 & 3.2 \\
\hline 823 & 2 & 42 & 12 & 823 1419.RAW & 13.3 & 0.69 & 801 & 0.7 & 557 & 1.0 & 1.8 \\
\hline 823 & 3 & 43 & 13 & 823_1518.RAW & 15.9 & 0.61 & 954 & 0.6 & 643 & 0.9 & 1.7 \\
\hline 823 & 4 & 44 & 14 & 823_1557.RAW & 16.2 & 0.59 & 974 & 0.6 & 660 & 0.9 & 1.9 \\
\hline \multirow{2}{*}{\multicolumn{5}{|c|}{$\begin{array}{r}\text { Average } \\
\text { Standard Deviation }\end{array}$}} & 15.3 & 0.63 & 916 & 0.6 & 628 & 0.9 & 2.2 \\
\hline & & & & & 1.16 & 0.04 & 69 & 0.0 & 42 & 0.1 & 0.5 \\
\hline
\end{tabular}


Three versions of the CRAB survey data were computed: (1) CRAB-IMU, which used the inertial measurement unit (IMU) to measure orientation, pitch and roll with all points retained; (2) CRAB Half-median, which is the CRAB-IMU data filtered to remove the largest outlier of every three points, and (3) CRAB Slope-Tilt, which used the measured slope of the beach to estimate the tilt (pitch only) of the CRAB. This was the first use of the IMU, and the two different versions allowed the IMU data to be compared to the Slope-Tilt computation used previously. CRAB data are not usually smoothed, so unlike the LARC data, no moving average smoothing was applied.

Table 3-2. Summary of LARC surveys.

\begin{tabular}{|c|c|c|c|c|c|c|c|c|c|c|c|c|}
\hline \multirow[b]{3}{*}{ Profile } & \multirow{2}{*}{\multicolumn{2}{|c|}{ Survey Number }} & \multirow[b]{3}{*}{ HYPACKfile } & \multirow{2}{*}{\multicolumn{2}{|c|}{ Survey Timing }} & \multicolumn{4}{|c|}{ Data Points } & \multirow[b]{3}{*}{$\begin{array}{l}\text { Latency } \\
\text { (s) }\end{array}$} & \multirow[b]{3}{*}{$\begin{array}{c}\text { Latency } \\
\text { standard } \\
\text { deviation } \\
\text { (cm) }\end{array}$} & \multirow[b]{3}{*}{ PDOP } \\
\hline & & & & & & \multicolumn{2}{|c|}{ Original } & \multicolumn{2}{|c|}{ Half-median \& Smooth } & & & \\
\hline & LARC-raw & \begin{tabular}{|c|} 
LARC Half- \\
median \& \\
Smooth \\
\end{tabular} & & $\begin{array}{c}\text { Elapsed } \\
\text { Time } \\
(\mathrm{min}) \\
\end{array}$ & $\begin{array}{c}\text { Speed } \\
(\mathrm{m} / \mathrm{s})\end{array}$ & Points & $\begin{array}{c}\text { Spacing } \\
(\mathrm{m})\end{array}$ & Points & $\begin{array}{c}\text { Spacing } \\
(\mathrm{m})\end{array}$ & & & \\
\hline 777 & 50 & 20 & 777 1302.RAW & 5.6 & 1.76 & 331 & 1.8 & 233 & 2.5 & -0.005 & 1.3 & 2.6 \\
\hline 777 & 51 & 21 & 777 1318.RAW & 5.2 & 1.96 & 301 & 2.0 & 212 & 2.9 & -0.010 & 1.1 & 2.1 \\
\hline 777 & 52 & 22 & 777_1333.RAW & 6.3 & 1.45 & 371 & 1.5 & 257 & 2.1 & -0.020 & 1.3 & 2.9 \\
\hline 777 & 53 & 23 & 777_1347.RAW & 5.2 & 1.88 & 308 & 1.9 & 216 & 2.7 & -0.030 & 1.2 & 3.2 \\
\hline 777 & 54 & 24 & 777_1410.RAW & 6.9 & 1.31 & 406 & 1.3 & 281 & 1.9 & -0.020 & 1.4 & 1.9 \\
\hline 777 & 55 & 25 & 777 1424.RAW & 4.6 & 1.97 & 275 & 2.0 & 193 & 2.8 & -0.025 & 1.3 & 1.6 \\
\hline 777 & 56 & 26 & 777 1436.RAW & 5.0 & 1.95 & 300 & 1.9 & 208 & 2.8 & -0.030 & 1.4 & 2.1 \\
\hline 777 & 57 & 27 & 777_1453.RAW & 5.6 & 1.87 & 328 & 1.9 & 233 & 2.7 & -0.025 & 1.4 & 2.2 \\
\hline 777 & 58 & 28 & 777 1511.RAW & 4.9 & 1.93 & 287 & 2.0 & 199 & 2.8 & -0.050 & 1.4 & 2.0 \\
\hline 823 & 50 & 20 & 823_1310.RAW & 5.6 & 1.94 & 332 & 2.0 & 232 & 2.8 & 0.020 & 1.3 & 1.9 \\
\hline 823 & 51 & 21 & 823_1325.RAW & 5.6 & 2.01 & 331 & 2.0 & 230 & 2.9 & -0.045 & 1.3 & 2.6 \\
\hline 823 & 52 & 22 & 823_1340.RAW & 5.0 & 1.91 & 295 & 1.9 & 206 & 2.8 & 0.070 & 1.6 & 3.1 \\
\hline 823 & 53 & 23 & 823_1352.RAW & 5.7 & 1.81 & 343 & 1.8 & 239 & 2.6 & 0.020 & 1.1 & 3.2 \\
\hline 823 & 54 & 24 & 823_1418.RAW & 4.7 & 1.94 & 283 & 1.9 & 198 & 2.8 & 0.050 & 1.0 & 2.0 \\
\hline 823 & 55 & 25 & 823_1430.RAW & 4.4 & 2.07 & 264 & 2.1 & 184 & 3.0 & -0.020 & 1.4 & 2.0 \\
\hline 823 & 56 & 26 & 823_1441.RAW & 4.8 & 2.12 & 282 & 2.1 & 198 & 3.1 & 0.020 & 1.5 & 2.1 \\
\hline 823 & 57 & 27 & 823_1504.RAW & 5.6 & 1.91 & 338 & 1.9 & 236 & 2.7 & 0.000 & 1.3 & 2.1 \\
\hline 823 & 58 & 28 & 823_1517.RAW & 4.7 & 2.01 & 278 & 2.0 & 195 & 2.9 & -0.005 & 1.3 & 2.0 \\
\hline \multirow{2}{*}{\multicolumn{4}{|c|}{$\begin{array}{r}\text { Average } \\
\text { Standard Deviation }\end{array}$}} & 5.3 & 1.88 & 314 & 1.9 & 219 & 2.7 & -0.006 & 1.3 & 2.3 \\
\hline & & & & 0.6 & 0.20 & 37 & 0.2 & 25 & 0.3 & 0.032 & 0.1 & 0.5 \\
\hline
\end{tabular}

As listed in Table 3-1 and Table 3-2, each analysis variation was assigned a unique survey number that corresponds to each survey pass of the profile line. These tables also list survey speed, point count, point spacing, and the observed position dilution of precision (PDOP). PDOP is a measure of the adequacy of the GPS satellite constellation. PDOP should be less than 4 and was under 3 during all surveying.

One of the attractions of the LARC system is its speed, and as shown in the tables, it is $\sim 3$ times faster than the CRAB. Since both systems use the same $1 \mathrm{~Hz}$ sampling, that translates into $\sim 3$ times more data points being collected by the CRAB than by the LARC.

Table 3-2 lists the computed latency between the GPS and echosounder data that resulted in the smoothest seafloor bottom trace. The column marked Latency Standard Deviation is a measure of that smoothness when the latency is applied. For these surveys, it averaged $1.3 \mathrm{~cm}$ indicating that the influence of surface waves was well removed. 


\section{Results}

In this section, the results of the evaluation are presented and discussed. The analysis is similar to that done by Clausner et al. (1986). The analysis assumes that each pass of the profile line is a valid representation of the actual profile shape and examines (1) the variation observed from multiple passes of each profile and (2) the difference between the LARC surveys and a reference profile created by combining the mean ATV and mean CRAB profiles. In all cases, the analysis is based on the defined cross section, and offline points are treated as though they were on the line.

\subsection{Analysis procedure}

To compute elevation statistics, the original data were resampled at a $1 \mathrm{~m}$ spacing using linear interpolation. That oversamples the LARC surveys and slightly undersamples the CRAB surveys. A $5 \mathrm{~m}$ spacing was also tried and found to produce similar results. Because a $1 \mathrm{~m}$ spacing is close to the $0.6 \mathrm{~m}$ spacing of the CRAB data, it produces a mean profile from the CRAB data that well resolves the general shape of the profile.

Note that since the CRAB is averaging between its back wheels and the LARC is rolling about in the waves and measuring a small patch of the bottom, neither system is able to resolve fine-scale bottom features such as ripples. Both systems are able to detect a change in bottom roughness when passing over bedforms with sufficient relief to physically rock the CRAB from side to side. When they exist, they are often found in the nearshore trough.

Four different zones are considered in the analysis, each posing different challenges for surveying:

1. Beach $(60-95 \mathrm{~m})$ - Both the CRAB and LARC are limited by their length in how close they can get to the base of the dune, which changes depending on whether they are moving onshore or offshore. The beach is typically planar alongshore and cross-shore, steepening near the water. Small position errors on slopes of $\sim 10 \mathrm{deg}$ will result in a few centimeters of elevation error.

2. Trough (96-190 m) - This zone can be deep with steep slopes and a rough bottom. The LARC starts to float in the trough and has to switch to marine propulsion. On returning, the LARC's front wheels hit the 
beach while the stern is lifted by following waves. Bubbles and turbidity may prevent the echosounder from detecting the bottom. Both the CRAB and the LARC can be challenged by loose, coarse sediments and may have trouble pulling onto the beach. The trough is the most challenging zone to survey.

3. Bar (191-230 m) - This zone can be steep if the bar is migrating onshore or more mildly sloping during quiescent periods. The CRAB may have trouble climbing the landward slope. For the LARC, this is where the waves may be breaking and where the wheels may again touch bottom. When traversing seaward in this zone, the echosounder transducer may come out of the water. This is less of a problem when the LARC is driving toward shore, and the LARC may even surf the waves. The bar zone is often three dimensional (3D) alongshore, which may affect survey repeatability as the LARC zigzags along the defined profile line.

4. Shoreface (231-600 m) - Once the bar zone is passed, both the CRAB and the LARC have a relatively easy time on the shoreface, which typically extends to $\sim 900 \mathrm{~m}$ for the $\mathrm{CRAB}$-being depth limited-and out to $\sim 2,000 \mathrm{~m}$ for the LARC. The main challenge on the shoreface for the LARC in deeper water is the accuracy of the sound speed profile.

\subsection{Repeatability}

In this section, all surveys for each system are inter-compared. Figure 4-1 shows the repetitive surveys for profile line 823 with the four CRAB-IMU surveys on the left and the nine LARC-raw surveys on the right (similar plots for both profile lines and all versions are included in Appendix A). The bottom panel shows the shape of the profile with a wide, deep trough and a bar with a steep shoreward face. The top panel shows the surveys in plan view with the CRAB surveys closer to the defined line than the LARC surveys.

Table 4-1 summarizes the online/offline statistics by survey zone. Overall, the CRAB stayed within $0.5 \pm 0.3 \mathrm{~m}$ of the line with the maximum range being only $1.5 \mathrm{~m}$. The statistic is consistent for all zones. The LARC took advantage of the low-wave conditions staying within $2.0 \pm 1 \mathrm{~m}$ of the line, which is better than a more usual operational range of $4 \pm 2.8 \mathrm{~m}$. The root mean square (RMS) error is consistent for the different zones, with the most spread found on the shoreface (offshore end of profile) resulting from points being collected as the LARC transitioned from line 777 to line 823. This can be seen in the top right panel of Figure 4-1. 
Figure 4-1. Cross-section plots of profile line 823. CRAB-IMU surveys are shown in the left panels; LARC-RAW data are shown in the right panels. Colors represent the different survey repetitions.

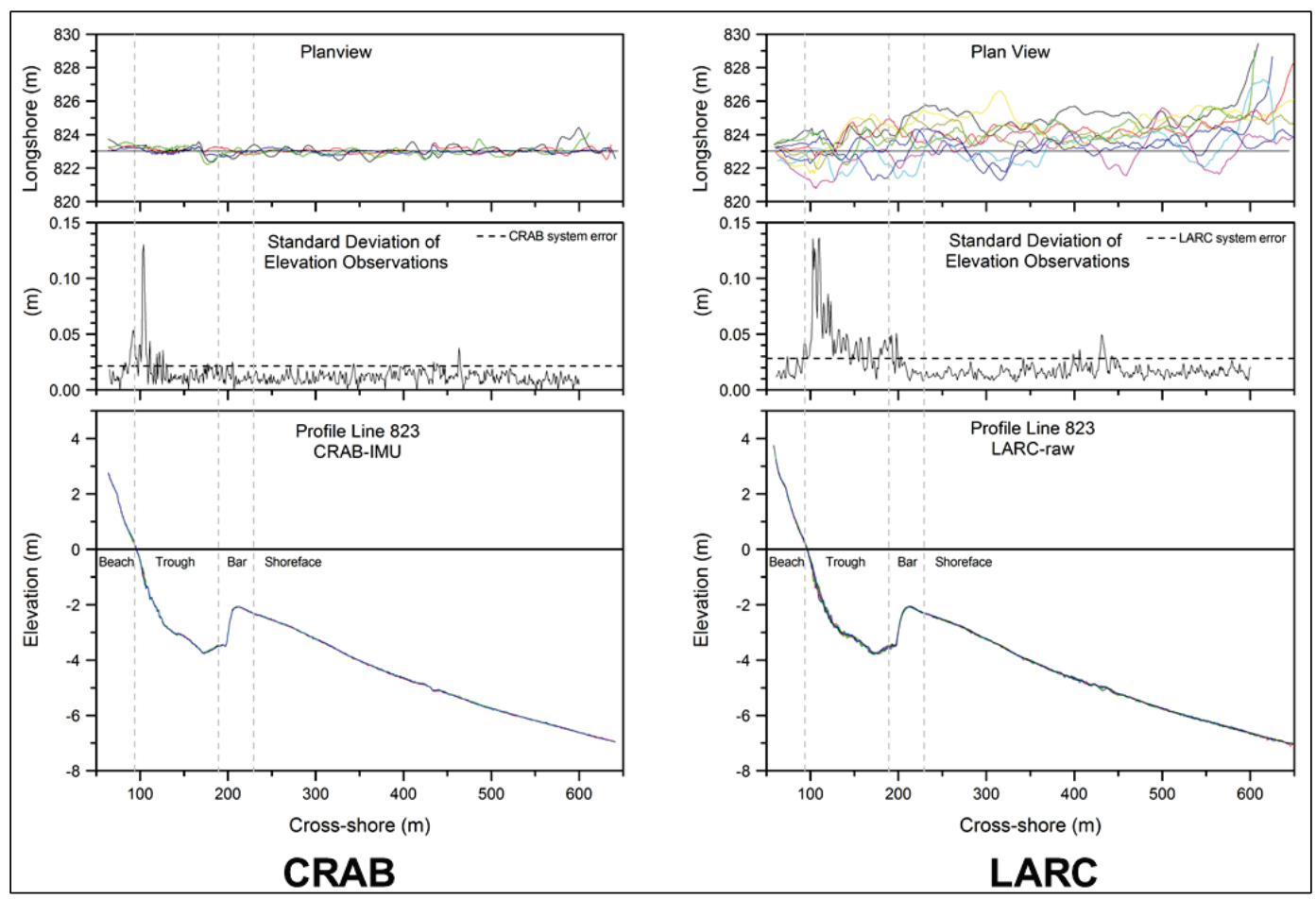

Table 4-1. Online/Offline statistics for the CRAB and LARC surveys by zones.

\begin{tabular}{|c|c|c|c|c|c|c|c|c|c|c|c|c|c|c|c|c|}
\hline & \multirow[b]{2}{*}{ Profile } & \multicolumn{3}{|c|}{ Overall } & \multicolumn{3}{|c|}{ Beach } & \multicolumn{3}{|c|}{ Trough } & \multicolumn{3}{|c|}{ Bar } & \multicolumn{3}{|c|}{ Shoreface } \\
\hline & & $\begin{array}{c}\text { Average } \\
\text { Range }\end{array}$ & $\begin{array}{c}\text { Max } \\
\text { Range }\end{array}$ & \begin{tabular}{|c|} 
Average \\
RMS \\
Error
\end{tabular} & $\begin{array}{c}\text { Average } \\
\text { Range }\end{array}$ & $\begin{array}{c}\text { Max } \\
\text { Range }\end{array}$ & \begin{tabular}{|c|} 
Average \\
RMS \\
Error
\end{tabular} & \begin{tabular}{|c} 
Average \\
Range
\end{tabular} & $\begin{array}{c}\text { Max } \\
\text { Range }\end{array}$ & \begin{tabular}{|c|} 
Average \\
RMS \\
Error
\end{tabular} & $\begin{array}{c}\text { Average } \\
\text { Range }\end{array}$ & $\begin{array}{l}\text { Max } \\
\text { Range }\end{array}$ & \begin{tabular}{|c|} 
Average \\
RMS \\
Error
\end{tabular} & $\begin{array}{c}\text { Average } \\
\text { Range }\end{array}$ & $\begin{array}{l}\text { Max } \\
\text { Range }\end{array}$ & $\begin{array}{c}\text { Average } \\
\text { RMS } \\
\text { Error }\end{array}$ \\
\hline \multirow[t]{3}{*}{ CRAB-IMU } & 777 & 0.7 & 1.5 & 0.3 & 1.0 & 1.5 & 0.5 & 0.7 & 1.1 & 0.4 & 0.7 & 1.1 & 0.4 & 0.6 & 1.2 & 0.3 \\
\hline & 823 & 0.4 & 1.4 & 0.2 & 0.4 & 0.7 & 0.3 & 0.4 & 0.9 & 0.2 & 0.4 & 0.6 & 0.2 & 0.4 & 1.4 & 0.2 \\
\hline & \begin{tabular}{|l|} 
average \\
\end{tabular} & 0.5 & 1.5 & 0.3 & 0.7 & 1.1 & 0.4 & 0.5 & 1.0 & 0.3 & 0.6 & 0.8 & 0.3 & 0.5 & 1.3 & 0.2 \\
\hline \multirow[t]{3}{*}{ LARC-raw } & 777 & 1.7 & 3.6 & 0.7 & 1.2 & 2.4 & 0.5 & 1.6 & 2.0 & 0.6 & 1.8 & 2.2 & 0.7 & 1.7 & 3.6 & 0.7 \\
\hline & 823 & 2.4 & 5.3 & 1.3 & 1.4 & 2.1 & 0.7 & 2.8 & 3.9 & 1.0 & 2.9 & 3.6 & 1.3 & 2.3 & 5.3 & 1.4 \\
\hline & \begin{tabular}{|l|} 
average \\
\end{tabular} & 2.0 & 4.4 & 1.0 & 1.3 & 2.3 & 0.6 & 2.2 & 3.0 & 0.8 & 2.4 & 2.9 & 1.0 & 2.0 & 4.4 & 1.0 \\
\hline
\end{tabular}

To put these numbers into perspective, although the CRAB is able to stay closer to the defined line, the LARC's maximum offline distance falls within the $7.6 \mathrm{~m}$ width of the CRAB (over which it averages the elevation).

The center panel of Figure 4-1 plots the average standard deviation of the measured elevation computed using all repetitions. This is a measure of the repeatability of the system and varies by zone and by method. This can be seen in Table 4-2 and in Figure 4-2, which compares the different filtering methods used. The horizontal dashed lines indicate the system error as described above. Almost all points on the shoreface fall under the system error for both the LARC and CRAB surveys. For the CRAB, only on the steep inshore side of the trough does the variation exceed the system error, reaching $13 \mathrm{~cm}$. This is a dynamic zone that may have changed 
during the course of the $2 \mathrm{hr}$ survey. The seaward side of the trough and the bar are well resolved by the CRAB with little variation. The application of the half-median smooth to the CRAB data has no significant impact on the vertical variation. Table 4-2 also includes the statistics for the CRAB data computed using the Slope-Tilt technique to estimate its tilt. This would only affect the zones where the CRAB tilts greater than $\sim 2$ deg (the beach, trough, and bar zones). The results are similar to the CRAB-IMU results.

The LARC data show increased variation over the trough and bar, though the maximum average standard deviation is similar and at the same location as the CRAB-the point in the survey where the LARC is entering or leaving the water. Application of the half-median +3-point moving average, does reduce the variation on the shoreward side of the trough but increases it on the bar where the steep face of the bar is smoothed by the averaging.

Table 4-2. Vertical variation statistics for the CRAB and LARC surveys by zones.

\begin{tabular}{|c|c|c|c|c|c|c|c|c|c|c|c|c|c|c|c|c|}
\hline & \multirow[b]{2}{*}{ Profile } & \multicolumn{3}{|c|}{ Overall } & \multicolumn{3}{|c|}{ Beach } & \multicolumn{3}{|c|}{ Trough } & \multicolumn{3}{|c|}{ Bar } & \multicolumn{3}{|c|}{ Shoreface } \\
\hline & & $\begin{array}{c}\text { Average } \\
\text { Range }\end{array}$ & $\begin{array}{c}\text { Max } \\
\text { Range }\end{array}$ & \begin{tabular}{|l|} 
Average \\
Std Dev
\end{tabular} & $\begin{array}{c}\text { Average } \\
\text { Range }\end{array}$ & $\begin{array}{c}\text { Max } \\
\text { Range }\end{array}$ & \begin{tabular}{|l|} 
Average \\
Std Dev
\end{tabular} & \begin{tabular}{|c|} 
Average \\
Range
\end{tabular} & $\begin{array}{c}\text { Max } \\
\text { Range }\end{array}$ & \begin{tabular}{|l|} 
Average \\
Std Dev
\end{tabular} & \begin{tabular}{|c|} 
Average \\
Range
\end{tabular} & $\begin{array}{c}\text { Max } \\
\text { Range }\end{array}$ & \begin{tabular}{|l|} 
Average \\
Std Dev
\end{tabular} & \begin{tabular}{|c|} 
Average \\
Range
\end{tabular} & \begin{tabular}{|c|} 
Max \\
Range
\end{tabular} & $\begin{array}{l}\text { Average } \\
\text { Std Dev }\end{array}$ \\
\hline \multirow{3}{*}{ CRAB-IMU } & 777 & 3.4 & 23.0 & 1.6 & 5.2 & 13.0 & 2.4 & 5.5 & 23.0 & 2.5 & 3.7 & 8.0 & 1.7 & 2.7 & 6.0 & 1.3 \\
\hline & 823 & 2.9 & 31.0 & 1.3 & 4.3 & 11.0 & 2.0 & 4.3 & 31.0 & 1.9 & 2.5 & 6.0 & 1.1 & 2.5 & 9.0 & 1.1 \\
\hline & average & 3.2 & 27.0 & 1.4 & 4.7 & 12.0 & 2.2 & 4.9 & 27.0 & 2.2 & 3.1 & 7.0 & 1.4 & 2.6 & 7.5 & 1.2 \\
\hline \multirow{3}{*}{$\begin{array}{l}\text { CRAB-IMU } \\
\text { half-median }\end{array}$} & 777 & 3.4 & 23.0 & 1.6 & 5.2 & 13.0 & 2.4 & 5.4 & 23.0 & 2.5 & 3.7 & 7.0 & 1.7 & 2.7 & 6.0 & 1.2 \\
\hline & 823 & 2.9 & 28.0 & 1.3 & 4.3 & 11.0 & 2.0 & 4.5 & 28.0 & 2.1 & 2.3 & 6.0 & 1.0 & 2.4 & 6.0 & 1.1 \\
\hline & average & 3.1 & 25.5 & 1.4 & 4.7 & 12.0 & 2.2 & 5.0 & 25.5 & 2.3 & 3.0 & 6.5 & 1.4 & 2.6 & 6.0 & 1.2 \\
\hline \multirow{3}{*}{$\begin{array}{l}\text { CRAB- } \\
\text { SlopeTilt }\end{array}$} & 777 & 3.3 & 25.0 & 1.5 & 4.4 & 14.0 & 2.1 & 5.0 & 25.0 & 2.3 & 3.7 & 7.0 & 1.7 & 2.7 & 6.0 & 1.2 \\
\hline & 823 & 2.9 & 29.0 & 1.3 & 4.4 & 11.0 & 2.1 & 4.1 & 29.0 & 1.9 & 2.4 & 6.0 & 1.1 & 2.5 & 9.0 & 1.1 \\
\hline & average & 3.1 & 27.0 & 1.4 & 4.4 & 12.5 & 2.1 & 4.6 & 27.0 & 2.1 & 3.1 & 6.5 & 1.4 & 2.6 & 7.5 & 1.2 \\
\hline \multirow{3}{*}{ LARC-raw } & 777 & 6.3 & 35.0 & 2.1 & 6.9 & 16.0 & 2.3 & 13.3 & 35.0 & 4.4 & 5.8 & 18.0 & 1.9 & 4.5 & 10.0 & 1.5 \\
\hline & 823 & 6.8 & 45.0 & 2.2 & 5.7 & 12.0 & 1.9 & 14.1 & 45.0 & 4.6 & 6.2 & 16.0 & 2.1 & 5.1 & 17.0 & 1.7 \\
\hline & average & 6.6 & 40.0 & 2.2 & 6.3 & 14.0 & 2.1 & 13.7 & 40.0 & 4.5 & 6.0 & 17.0 & 2.0 & 4.8 & 13.5 & 1.6 \\
\hline \multirow{3}{*}{$\begin{array}{l}\text { LARC half- } \\
\text { median } \\
\text { smooth }\end{array}$} & 777 & 5.9 & 35.0 & 2.0 & 6.8 & 16.0 & 2.3 & 11.9 & 35.0 & 3.9 & 8.4 & 24.0 & 2.8 & 4.1 & 9.0 & 1.3 \\
\hline & 823 & 6.5 & 30.0 & 2.1 & 5.7 & 12.0 & 1.9 & 12.2 & 30.0 & 3.9 & 10.3 & 30.0 & 3.5 & 4.7 & 11.0 & 1.5 \\
\hline & average & 6.2 & 32.5 & 2.0 & 6.2 & 14.0 & 2.1 & 12.1 & 32.5 & 3.9 & 9.3 & 27.0 & 3.2 & 4.4 & 10.0 & 1.4 \\
\hline
\end{tabular}


Figure 4-2. Variation in the standard deviation of elevation for all survey repetitions for profile line 823.

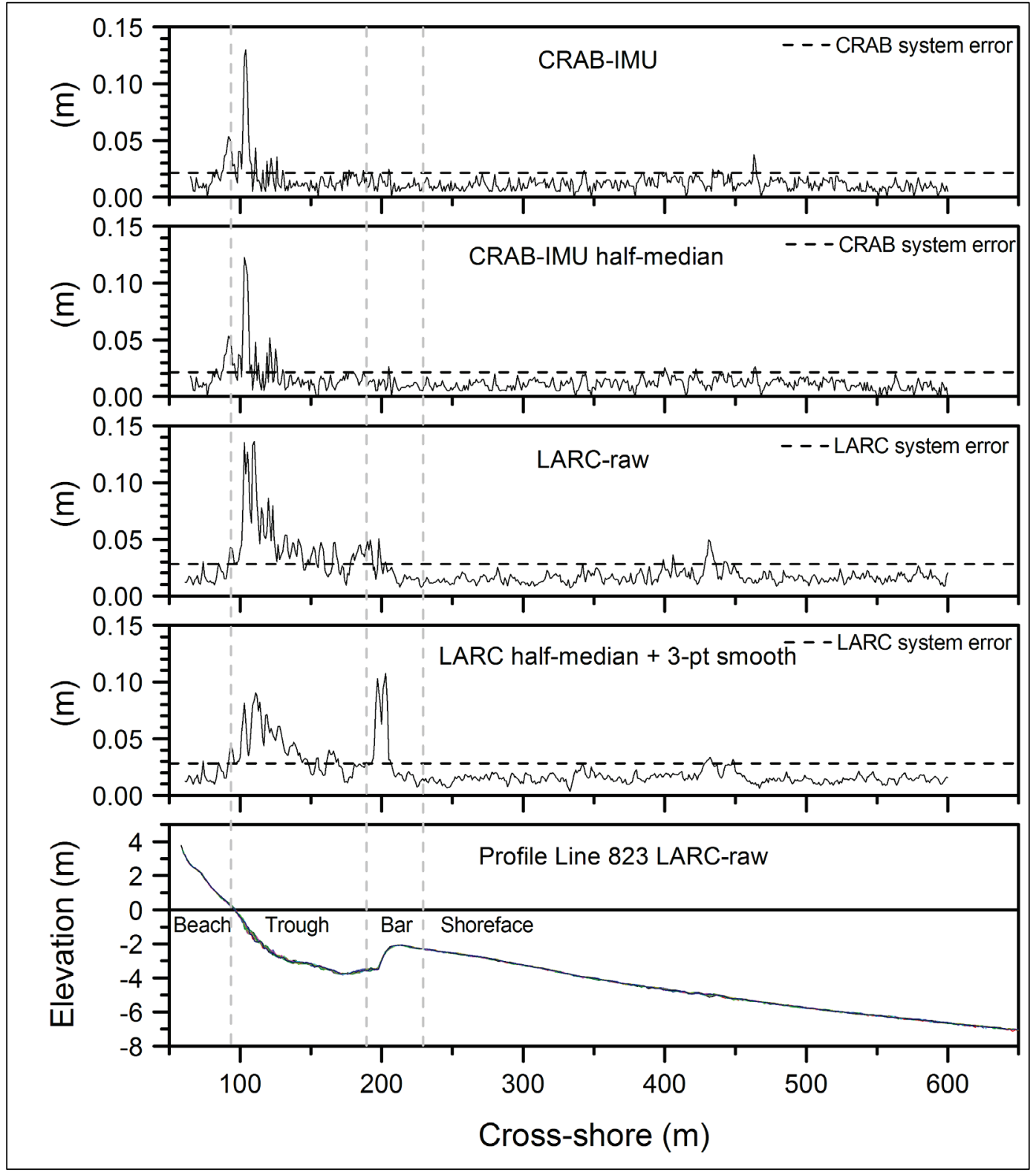

\subsection{Elevation accuracy of the LARC surveys}

To evaluate the accuracy of the LARC, the LARC data were compared to a reference profile computed from the mean ATV and CRAB surveys. The development of the reference profile is shown in Figure 4-3, which overplots the computed mean profile with the original surveys and which illustrates how well even small features of the profile are captured in each repetition (panels A, B, and C). The steep rise of the bar (panel B) is well resolved by each of the repetitions as is a pattern of roughness in the trough (panel A). Also interesting is an unusual and repeated dip on the 
shoreface (panel C). This feature was not observed on line 777 just $46 \mathrm{~m}$ to the south. What is unknown is which wheel of the CRAB, or both, is responding to this feature.

Figure 4-3. The reference profile for the CRAB-IMU surveys of 823. Colors represent different repetitions used in computing the mean profile.

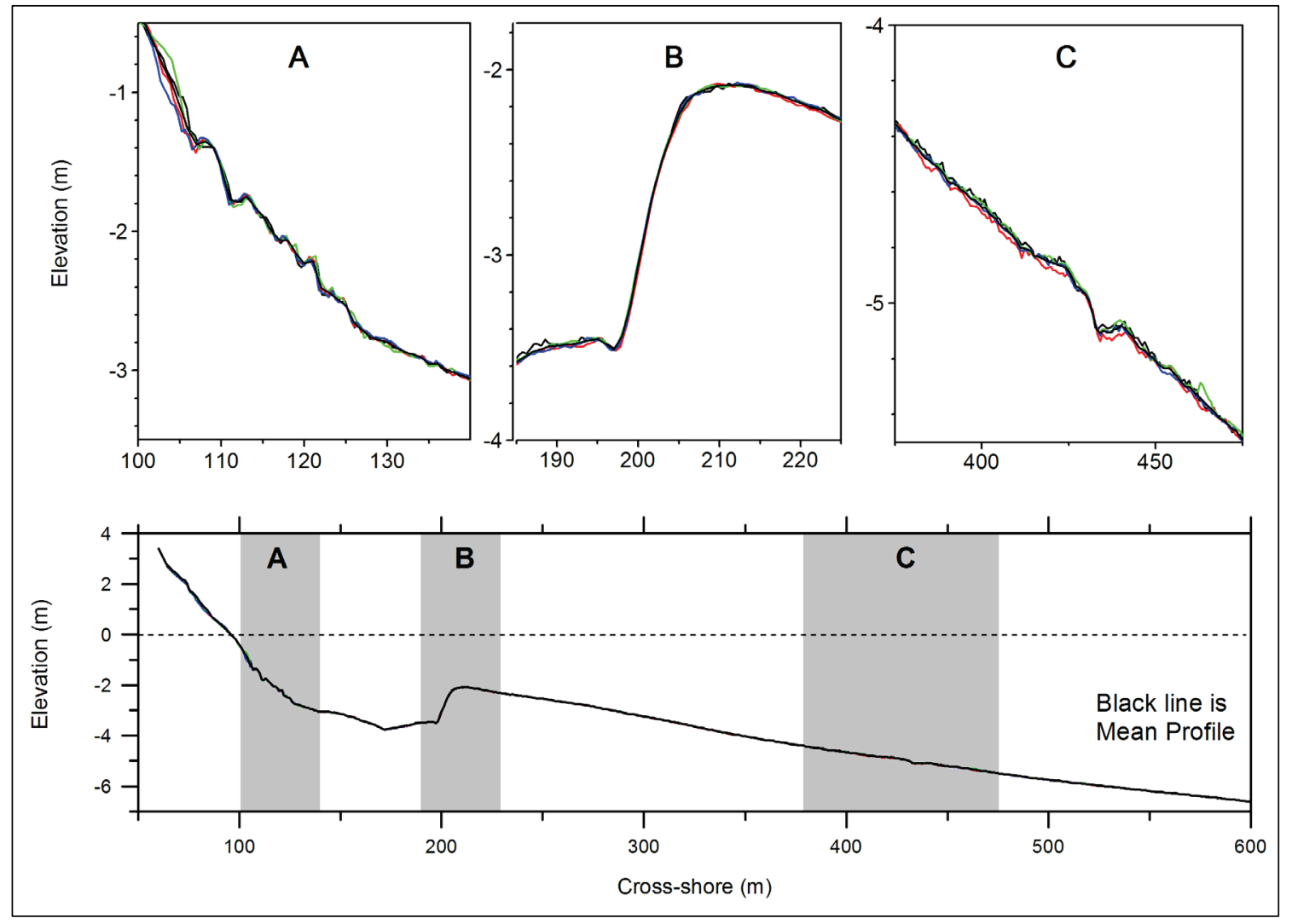

Because of this, it is not expected that the LARC, which is surveying a small bottom patch defined by the beam width of the transducer, will match the CRAB data exactly-as they are measuring different features of the bottom. They should however match where Figure 4-4 compares the nine LARC repetitions of profile line 823 to the reference profile. In general, the fit is very good, particularly over the steep bar (panel B). Offshore, the LARC surveys reflect the bottom roughness seen by the $\mathrm{CRAB}$, but as expected, not exactly. What is also interesting is that while the half-median +3 -point smooth has negligible impact on panels $\mathrm{A}$ and $\mathrm{C}$, it significantly alters the shape of the bar (panel B). 
Figure 4-4. Profile line 823 surveys relative to the mean profile. Colors represent different LARC survey repetitions.
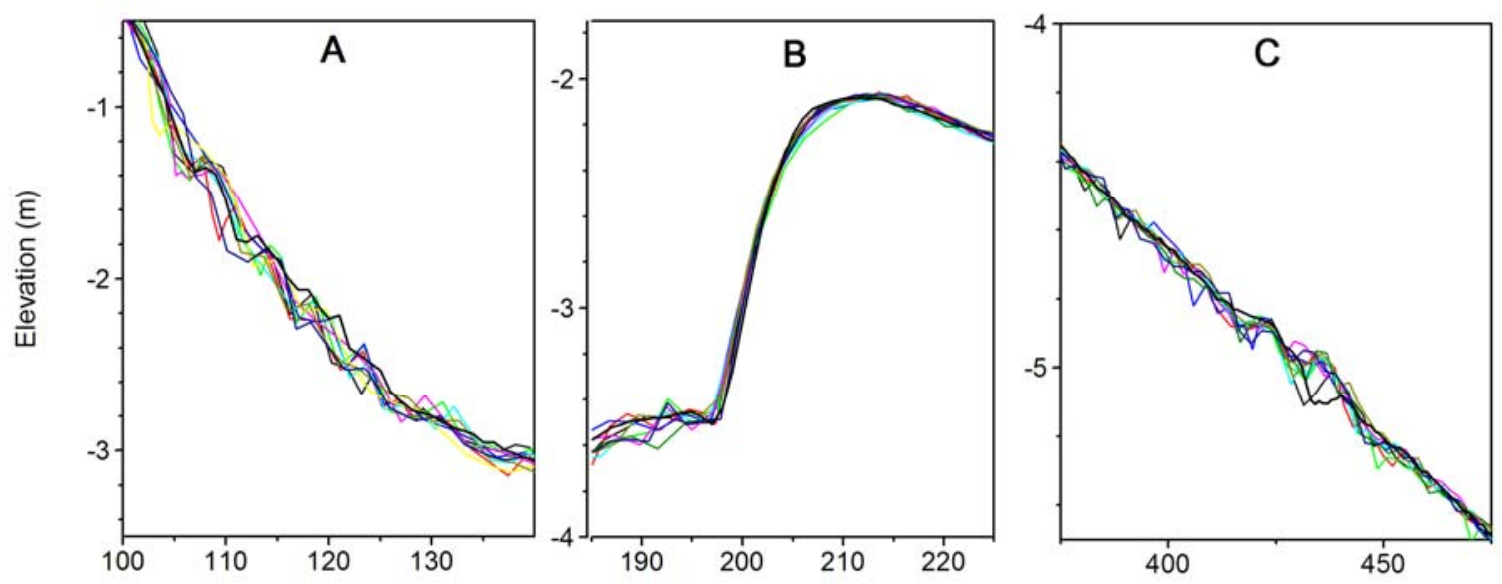

Profile Line 823 - LARC-half median
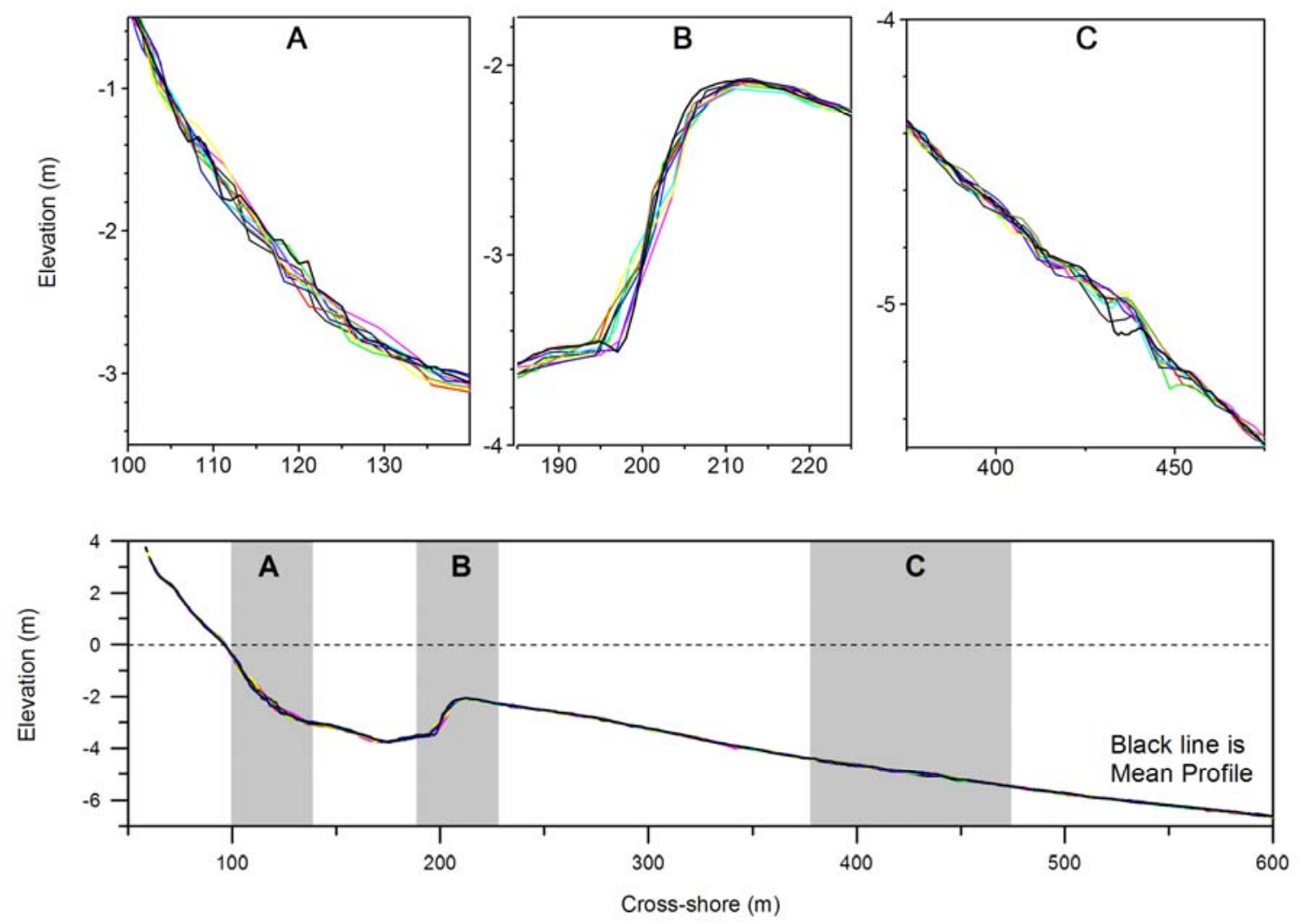

The original, unsmoothed LARC data are better at capturing the steep shape of the bar as measured with the CRAB. Smoothing should be avoided in the bar/ trough zone, and based on these results may not be needed elsewhere. The raw difference data are shown in Figure 4-5 for 
both profile lines 777 (left) and 823 (right). Differences are greater in the trough, are smaller seaward of the bar, and then increase slightly seaward of $\sim 500 \mathrm{~m}$. The spike in the RMS error on line 823 at $\sim 430 \mathrm{~m}$ results from the different way each system measures the dip/roughness in that specific location. On the shoreface, outside of the one feature on line 823, is where the two systems are expected to agree. There is good agreement on the inner shoreface. On the outer shoreface, the LARC data fall below the reference profile with the difference increasing slightly with increasing distance. The difference is small but notable with measured RMS error falling just above the system error.

Figure 4-5. Comparison between the LARC-raw elevation data and the reference profile for Profile Lines 777 (left panel) and 823 (right panel).
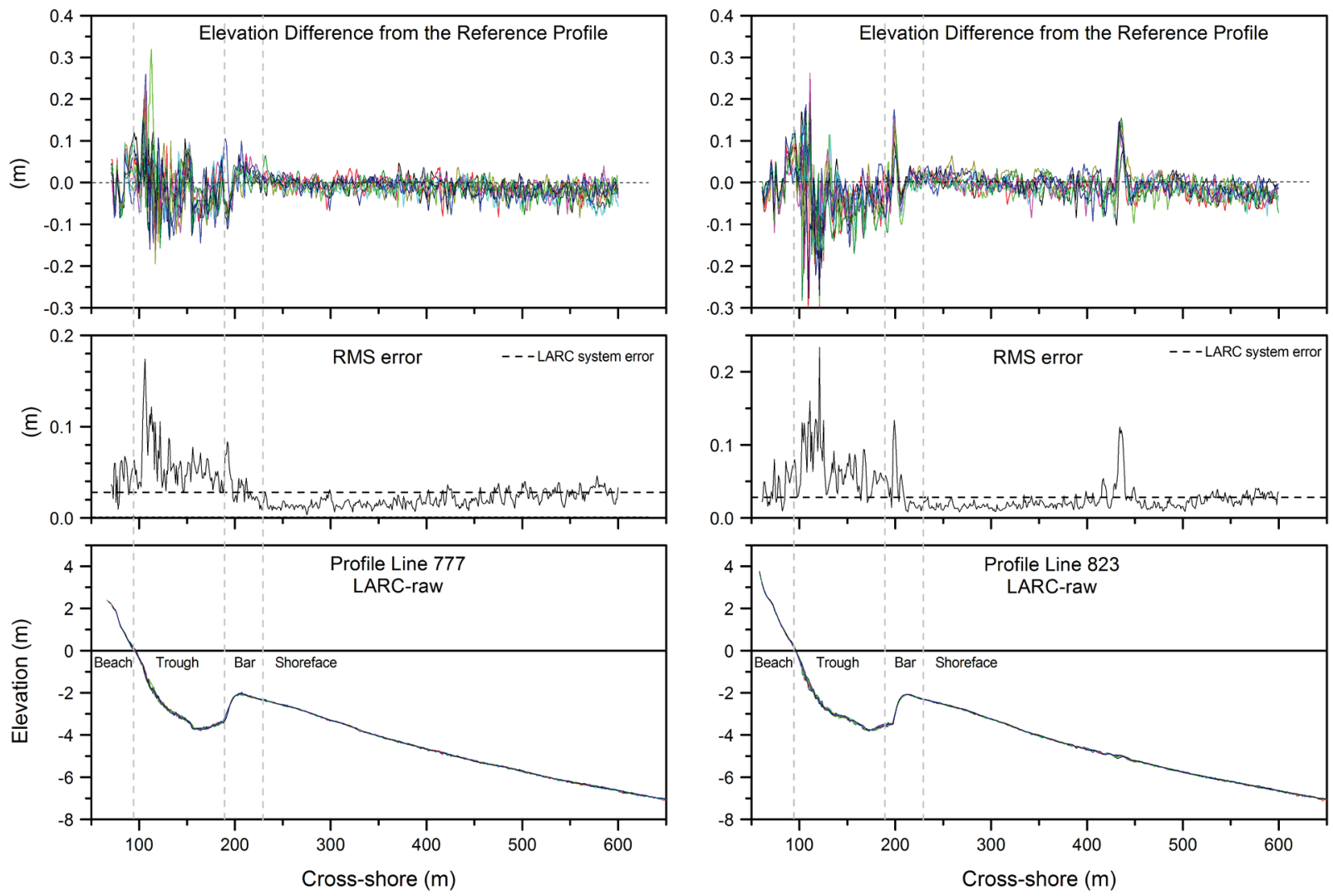

This can be seen in Table 4-3 which summarizes the difference data by zones. There is a slight overall negative bias indicating that the LARC data are $\sim 1 \mathrm{~cm}$ lower than the reference profile, well within the accuracy of these measuring systems. Average RMS error is $3.1 \mathrm{~cm}$, varying from 6.4 $\mathrm{cm}$ in the trough to $2.2 \mathrm{~cm}$ on the shoreface. 
Table 4-3. Vertical error statistics for the LARC, relative to the reference profile by zones.

\begin{tabular}{|c|c|c|c|c|c|c|c|c|c|c|c|}
\hline & \multirow[b]{2}{*}{ Profile } & \multicolumn{2}{|c|}{ Overall } & \multicolumn{2}{|c|}{ Beach } & \multicolumn{2}{|c|}{ Trough } & \multicolumn{2}{|c|}{ Bar } & \multicolumn{2}{|c|}{ Shoreface } \\
\hline & & \begin{tabular}{c|} 
Average \\
Difference
\end{tabular} & \begin{tabular}{|c|} 
Average \\
RMS \\
Error \\
\end{tabular} & $\begin{array}{l}\text { Average } \\
\text { Difference }\end{array}$ & \begin{tabular}{|c|} 
Average \\
RMS \\
Error \\
\end{tabular} & $\begin{array}{c}\text { Average } \\
\text { Difference }\end{array}$ & $\begin{array}{c}\text { Average } \\
\text { RMS } \\
\text { Error }\end{array}$ & $\begin{array}{c}\text { Average } \\
\text { Difference }\end{array}$ & \begin{tabular}{|c|} 
Average \\
RMS \\
Error
\end{tabular} & \begin{tabular}{|c|} 
Average \\
Difference
\end{tabular} & $\begin{array}{c}\text { Average } \\
\text { RMS } \\
\text { Error } \\
\end{array}$ \\
\hline \multirow{3}{*}{$\begin{array}{l}\text { LARC- } \\
\text { HalfMedian- } \\
\text { Mean }\end{array}$} & 777 & -1.0 & 2.8 & 0.4 & 4.5 & -0.6 & 5.3 & -1.3 & 4.3 & -1.2 & 1.9 \\
\hline & 823 & -1.1 & 3.3 & 0.4 & 4.2 & -3.5 & 6.4 & 0.0 & 6.0 & -0.7 & 2.2 \\
\hline & average & -1.1 & 3.1 & 0.4 & 4.3 & -2.1 & 5.8 & -0.6 & 5.1 & -1.0 & 2.0 \\
\hline \multirow{3}{*}{$\begin{array}{l}\text { LARC-raw- } \\
\text { Mean }\end{array}$} & 777 & -1.0 & 2.9 & 0.4 & 4.5 & -1.0 & 5.9 & 0.4 & 3.1 & -1.2 & 2.0 \\
\hline & 823 & -1.1 & 3.3 & 0.4 & 4.2 & -3.9 & 7.0 & 0.9 & 3.5 & -0.7 & 2.3 \\
\hline & average & -1.0 & 3.1 & 0.4 & 4.3 & -2.5 & 6.4 & 0.6 & 3.3 & -1.0 & 2.2 \\
\hline
\end{tabular}

\subsection{Beach survey compared to the ATV}

To gauge how accurate the LARC and CRAB are at surveying the beach, the data were compared to that collected by the ATV. Although the overlap was limited ( $15 \mathrm{~m}$ on profile line 777 and $20 \mathrm{~m}$ on line 823 ), both systems fell consistently below the ATV survey: the LARC by $1.7 \mathrm{~cm}$ and the CRAB by $6.3 \mathrm{~cm}$. There are several possible explanations for this difference. The LARC is not corrected for its tilt on the beach; both systems survey a wider track than the ATV, and neither system adjusts for sinking into the sand. More data from a wider beach are needed to examine this difference in detail.

\subsection{Comparison to Clausner et al. (1986)}

Clausner et al. (1986) examined the accuracy of the CRAB using an electronic total station and a boat equipped with a digital echosounder and a microwave positioning system, all pre-GPS technology. To put the results presented here into perspective, it is interesting to compare this study to the one completed in 1986 . Vertical repeatability of the CRAB data has improved from 5.4 to $1.8 \mathrm{~cm}$, and for the floating platforms (boat/LARC) it has improved from $31.1 \mathrm{~cm}$ to $2.2 \mathrm{~cm}$. Their boat data had an offset from the CRAB mean profile that increased offshore and averaged $22.6 \mathrm{~cm}$, attributed possibly to a squat correction. Here, that offset is $\sim 1 \mathrm{~cm}$ with an average RMS error of $3.1 \mathrm{~cm}$. These results show a significant improvement in accuracy with modern nearshore surveying. 


\section{Summary}

This report discusses the results of an evaluation of nearshore survey accuracy using the CRAB and LARC equipped with RTK-GPS for positioning and on the LARC, a digital echosounder to measure depth. Both vehicles were also equipped with motion sensors. The accuracy of the CRAB, in operation since 1981, is well established. However, the LARC as a survey platform has some significant advantages: three times faster, not depth-limited, and transportable. It also has some disadvantages: waveheight limited and gaps occur in the echosounder data due to turbidity and bubbles, obscuring the bottom. Therefore, a main objective was to determine how data collected with the LARC, under ideal survey conditions, compare to the CRAB.

The field test consisted of repetitively surveying two profile lines (777 and 823): four times by the CRAB, nine times by the LARC. An ATV was used to survey the subaerial beach. The CRAB and ATV data were averaged to define a reference profile shape for use in determining the accuracy of the LARC surveys.

The two measuring systems differ. The CRAB measures elevation based on the known height of its GPS antenna above the ground. On steep parts of the profile, the tilt is measured and adjusted for in the elevation computation. The measured elevation is actually an average of the elevation under the rear two wheels, which are $8.3 \mathrm{~m}$ apart. The amphibious LARC measures elevation on land based on the height of its GPS antenna above the ground. Once floating, it is subject to motion from wave-induced rolling, and the elevation is based on combining the GPS, echosounder, and motion readings to remove wave motion and tide. The LARC measurement of elevation is based on sensing a small patch of the bottom, the size of which is determined by the beam width of the echosounder (typically $<1.0 \mathrm{~m}$ ).

The two systems were found to compare extremely well with a mean difference of $\sim 1 \mathrm{~cm}$, well within measurement accuracy although slight differences exist. The two systems compared best on the mildly sloping, shore-parallel shoreface, which is seaward of the nearshore sandbar and where the two measuring systems differ the least. The RMS error between the LARC measurements and the CRAB mean profile was $2.2 \mathrm{~cm}$. Across the trough and over the sandbar, the RMS error, although still small, 
increased to 6.4 and $3.3 \mathrm{~cm}$, respectively. However, this difference should be expected as in these zones the two systems are measuring slightly different aspects of the profile shapes. The CRAB averages between its back wheels (GPS antenna is centered between wheels) while the LARC measures directly under the echosounder between the front two tires. On the beach, both the LARC and CRAB surveys fell below the ATV elevation, averaging $2 \mathrm{~cm}$ for the LARC and $6 \mathrm{~cm}$ for the $\mathrm{CRAB}$, an indication that either the tilt or sinking in the sand is not fully accounted for.

With the development of RTK-GPS, nearshore survey accuracy has improved. Compared to the study of Clausner et al. (1986), vertical repeatability of the CRAB data has improved from 5.4 to $1.8 \mathrm{~cm}$, and for the floating platforms (boat/LARC) it has improved from $31.1 \mathrm{~cm}$ to $2.2 \mathrm{~cm}$. Their boat data had an offset that increased offshore and averaged $22.6 \mathrm{~cm}$. Here, that offset is $\sim 1 \mathrm{~cm}$ with an average RMS error of just $3.1 \mathrm{~cm}$. 


\section{References}

Birkemeier, W. A., and C. Mason. 1984. "The CRAB: A Unique Nearshore Surveying Vehicle.” American Society of Civil Engineers, Journal of Surveying Engineering 110(1): 1-7.

Clausner, J. E., W. A. Birkemeier, and G. R. Clark. 1986. Field Comparison of Four Nearshore Survey Systems. CERC MP-86-6. Vicksburg, MS: U.S. Army Engineer Waterways Experiment Station, Coastal Engineering Research Center.

Howd, P. A., and W. A. Birkemeier. 1987. Beach and Nearshore Survey Data: 19811984. CERC-87-9. Vicksburg, MS: U.S. Army Engineer Waterways Experiment Station.

Lee, G. H., and W. A. Birkemeier. 1993. Beach and Nearshore Survey Data: 1985-1991. CERC-93-3. Vicksburg, MS: U.S. Army Engineer Waterways Experiment Station.

Trimble Navigation Limited. 2003. 5700/580o GPS Receiver User Guide Version 2.00 Revision A, 454-1099. Dayton, OH: Trimble Navigation Limited Engineering and Construction Division.

https://www.ngs.noaa.gov/corbin/class description/57005800V2UserGuide.pdf 


\section{Appendix A: Cross-Section Survey Plots}

This appendix includes raw data plots for each profile line surveyed and data filtering method used.

Figure A-1. Plot of the four repetitions of the CRAB-IMU data on profile line 777.

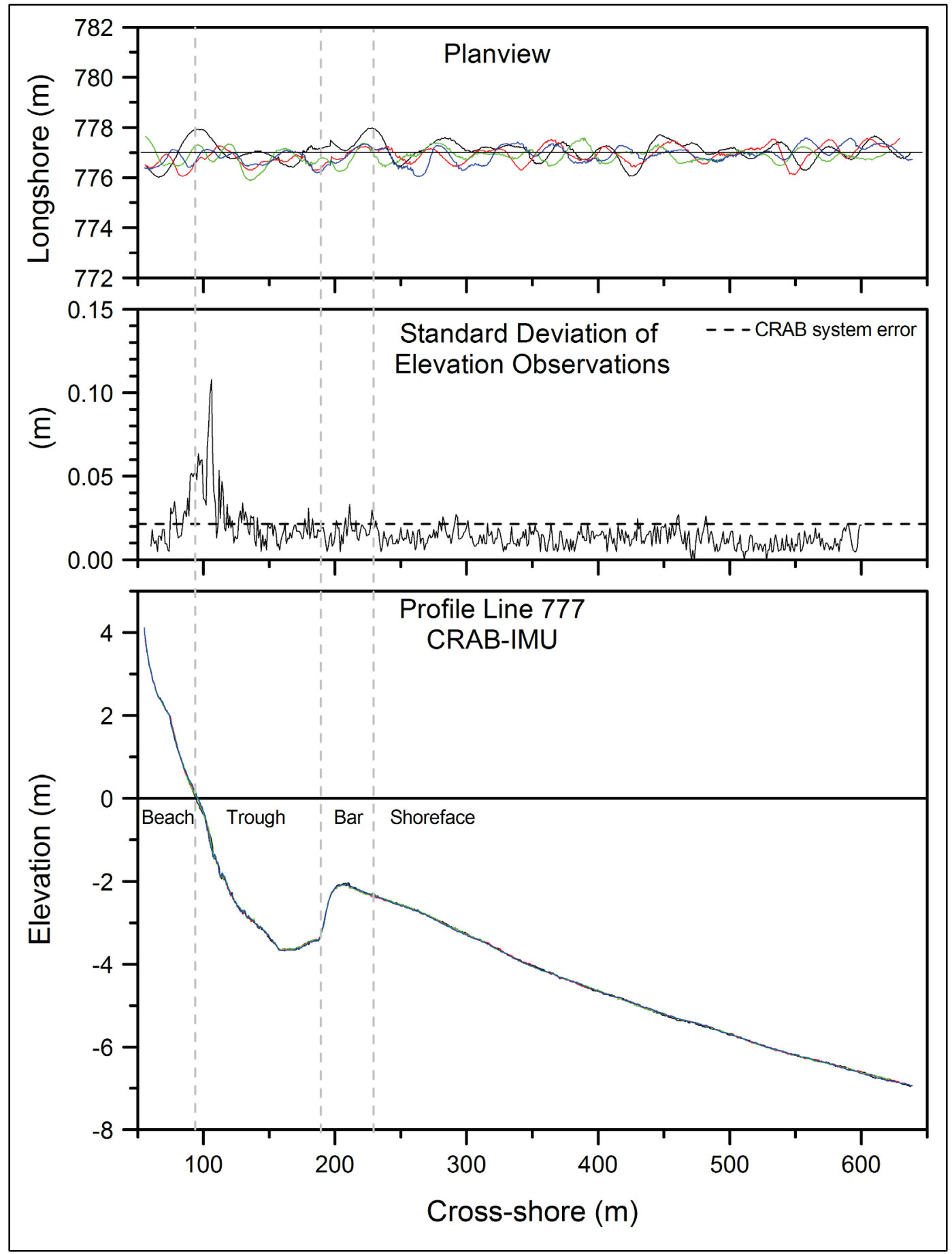


Figure A-2. Plot of the four repetitions of the CRAB-IMU half-median data on profile line 777.

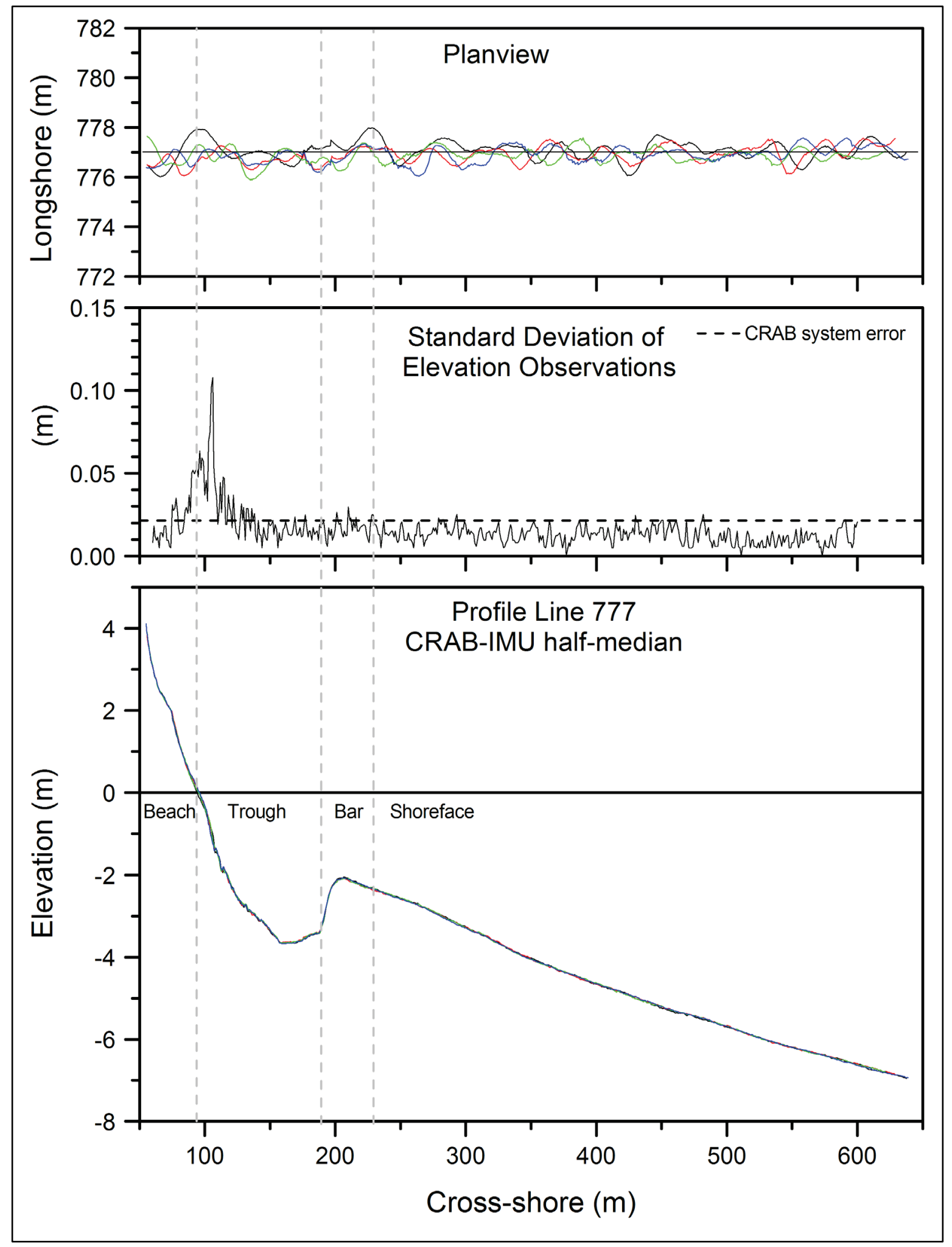


Figure A-3. Plot of the nine repetitions of the LARC-raw data on profile line 777.

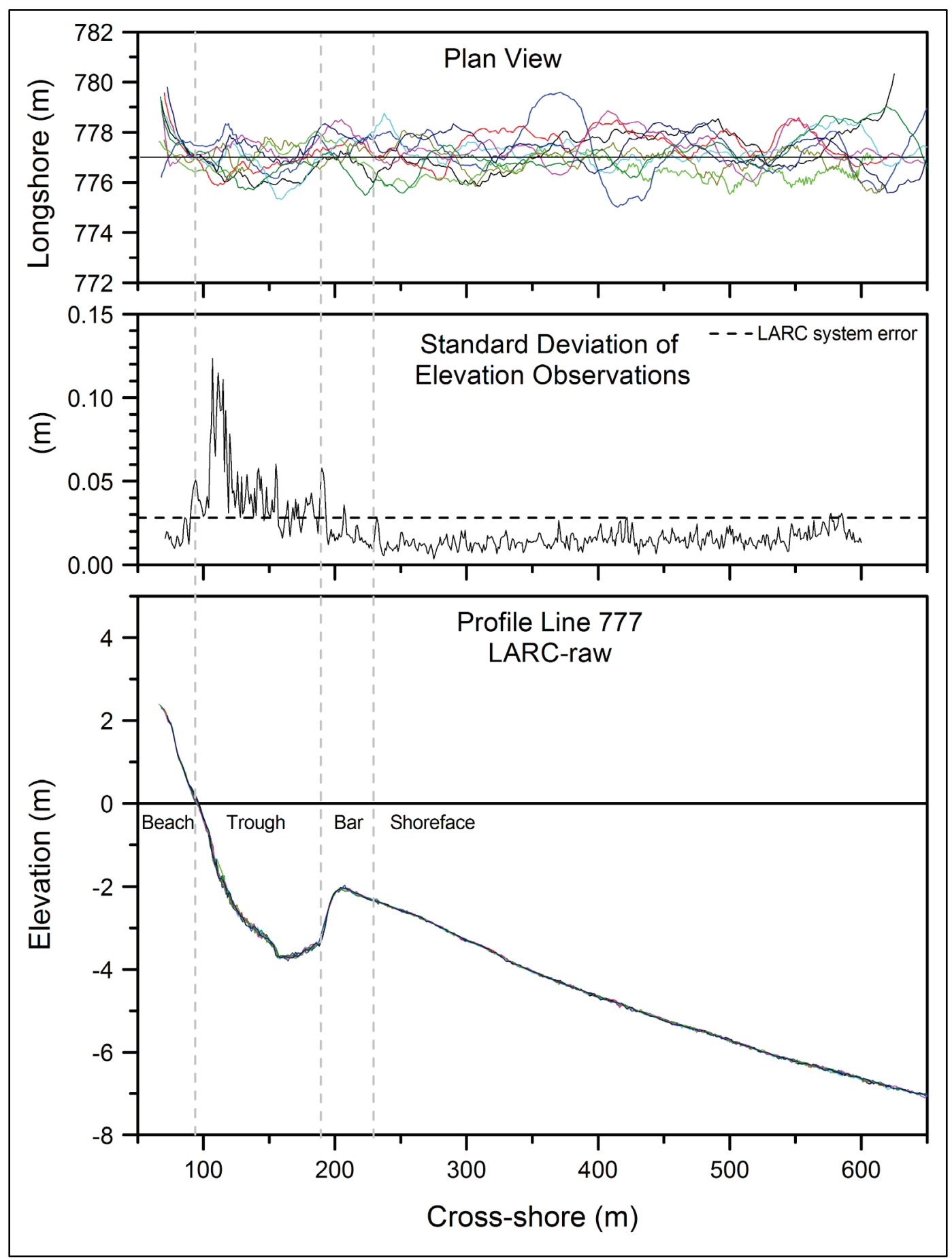


Figure A-4. The nine repetitions of the LARC half-median $+3 \mathrm{pt}$ smooth data on profile line 777.

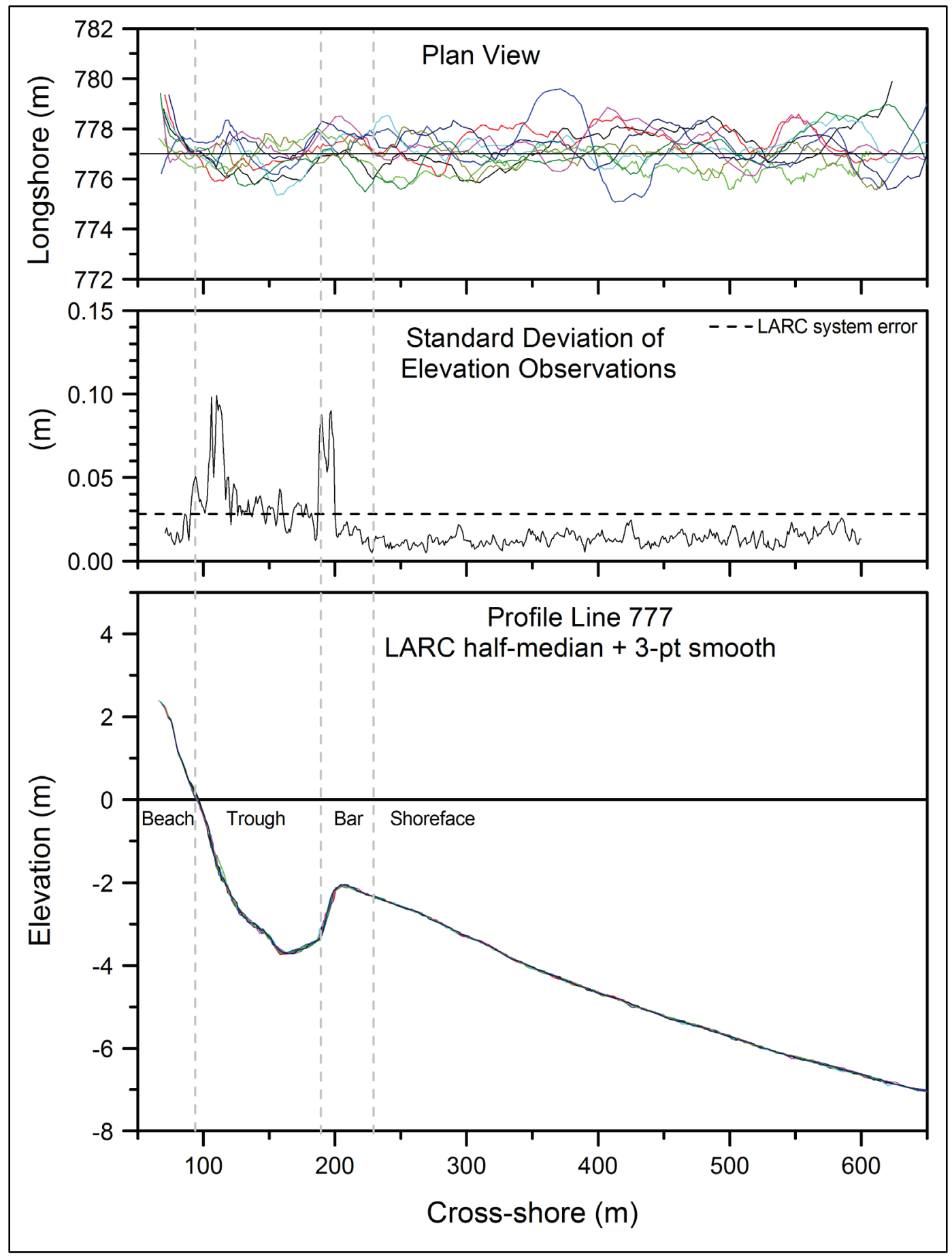


Figure A-5. The nine repetitions of the CRAB-IMU data on profile line 823 .

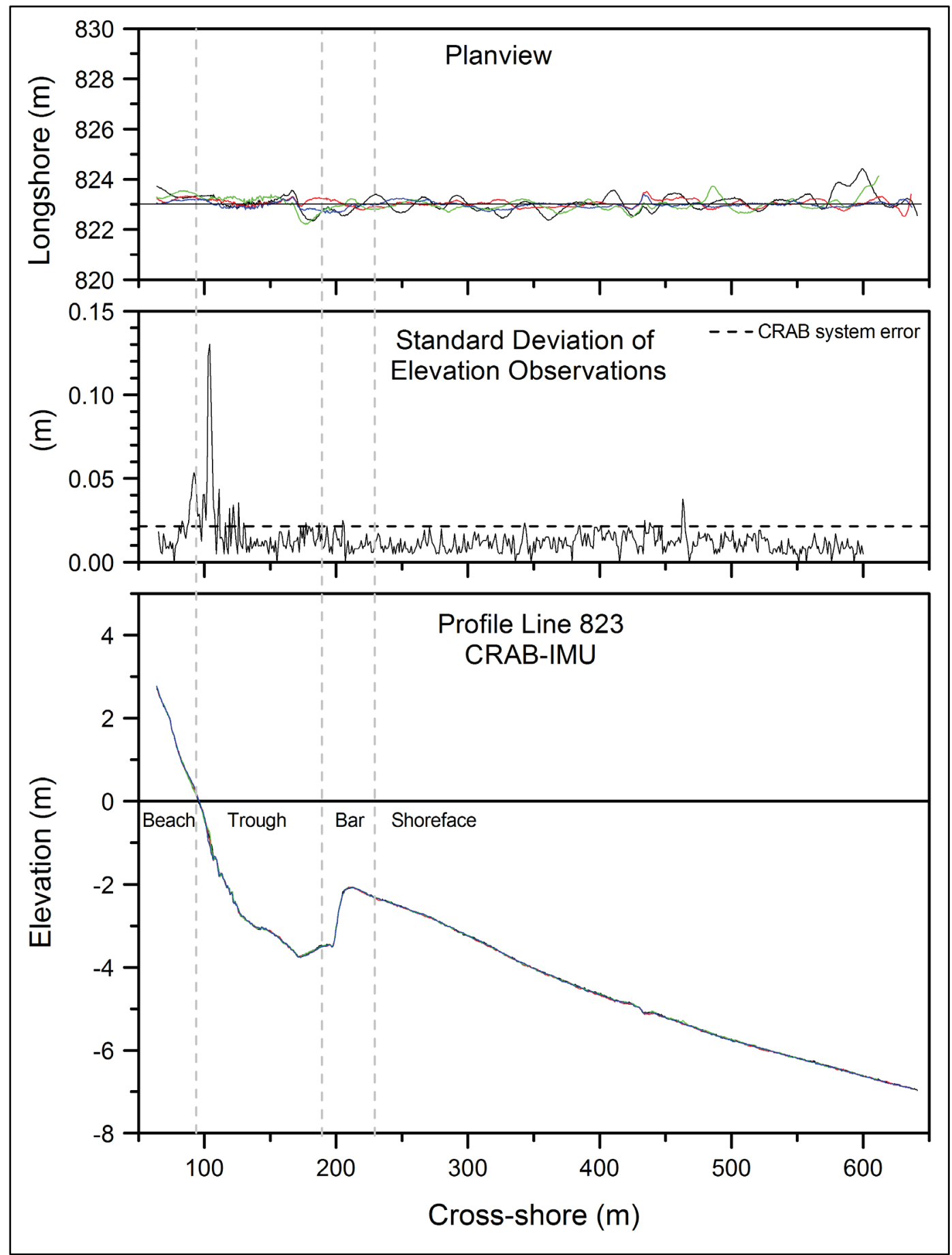


Figure A-6. The four repetitions of the CRAB-IMU half-median data on profile line $\mathbf{8 2 3 .}$

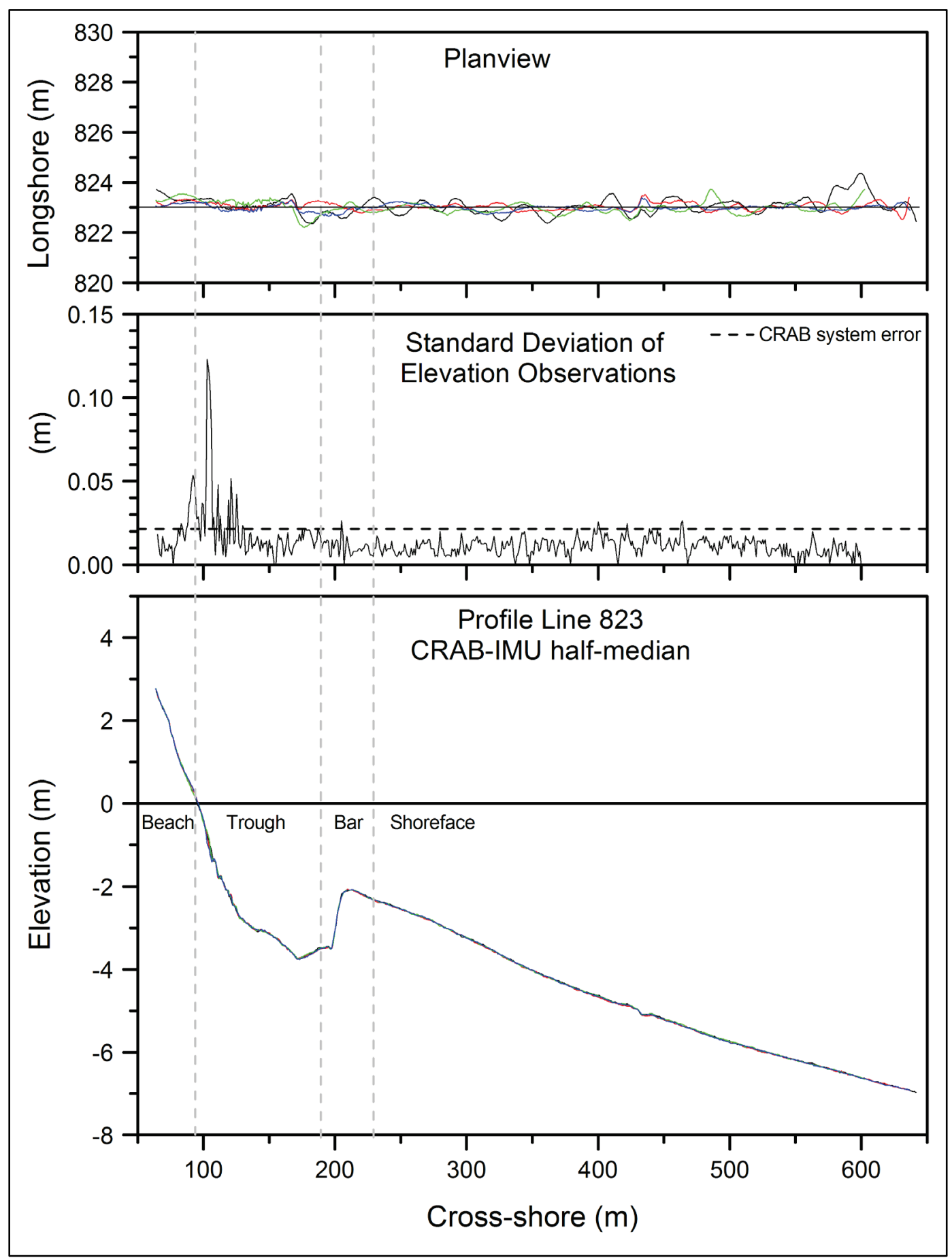


Figure A-7. The nine repetitions of the LARC-raw data on profile line 823.

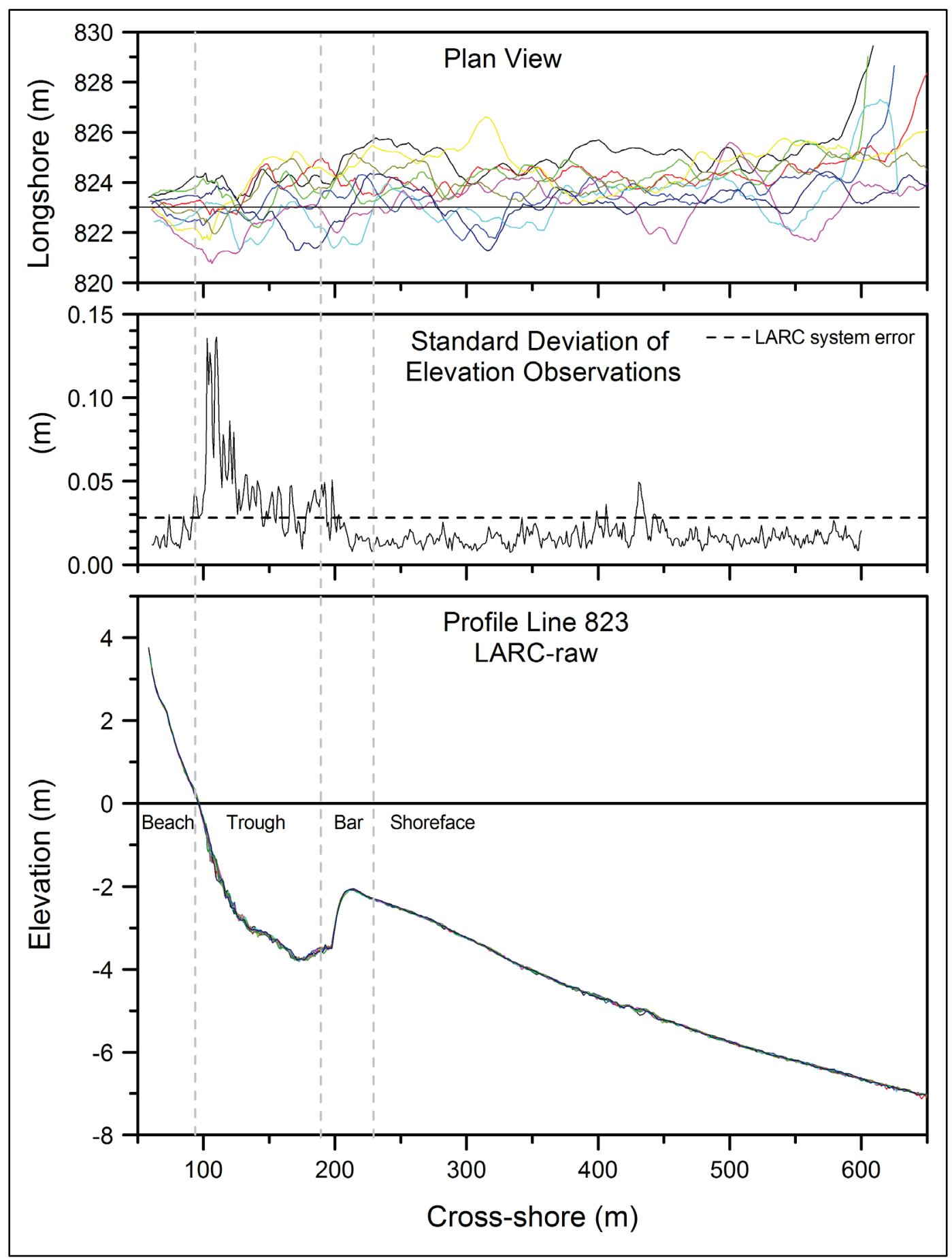


Figure A-8. The nine repetitions of the LARC half-median +3-point smooth data on profile line 823.

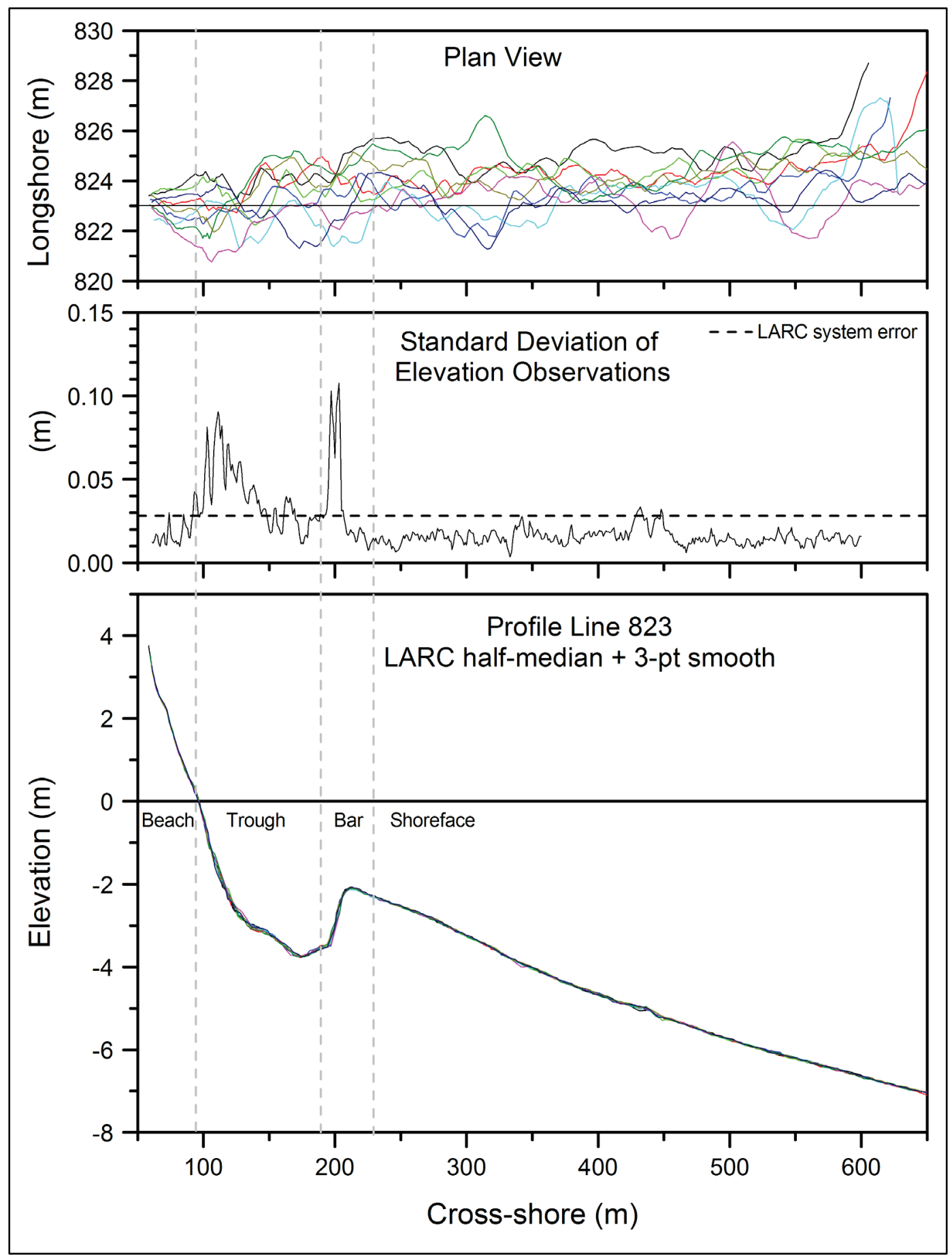




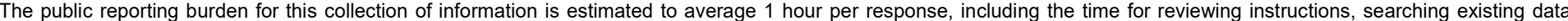

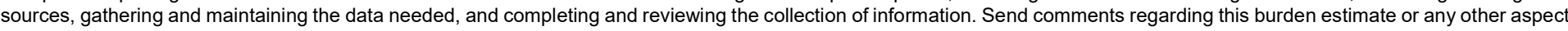

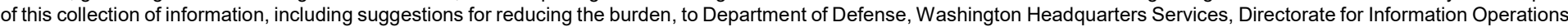

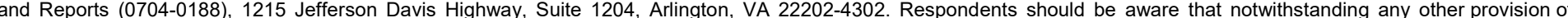
law, no person shall be subject to any penalty for failing to comply with a collection of information if it does not display a currently valid OMB control number.

PLEASE DO NOT RETURN YOUR FORM TO THE ABOVE ADDRESS.

\begin{tabular}{|l|l|l}
\hline 1. REPORT DATE & 2. REPORT TYPE & 3. DATES COVERED (FrOm - To)
\end{tabular}

December 2017

Final Report

\section{TITLE AND SUBTITLE}

Nearshore Survey System Evaluation

\section{DATES COVERED (From - To)}

5a. CONTRACT NUMBER

5b. GRANT NUMBER

5c. PROGRAM ELEMENT NUMBER

462585

6. AUTHOR(S)

Michael F. Forte, William A. Birkemeier, and J. Robert Mitchell 5d. PROJECT NUMBER

5e. TASK NUMBER

5f. WORK UNIT NUMBER

8. PERFORMING ORGANIZATION REPORT NUMBER

ERDC/CHL TR-17-19

10. SPONSOR/MONITOR'S ACRONYM(S) USACE

11. SPONSOR/MONITOR'S REPORT NUMBER(S)

\section{DISTRIBUTION/AVAILABILITY STATEMENT}

Approved for public release; distribution is unlimited.

\section{SUPPLEMENTARY NOTES}

\section{ABSTRACT}

This report evaluates the accuracy of two systems for surveying the beach and nearshore zone. The 10-meter (m)-tall Coastal Research Amphibious Buggy (CRAB) and the $10 \mathrm{~m}$ long Lighter Amphibious Resupply Cargo (LARC). The accuracy of the CRAB, in operation since 1981, to do centimeter-level surveys is well established. The main objective of this evaluation was to determine how well data collected with the LARC, under ideal survey conditions, compared to the CRAB. The field test consisted of repetitively surveying two profile lines (777 and 823): four times by the CRAB, nine times by the LARC. An all terrain vehicle (ATV) was used to survey the subaerial beach. The CRAB and ATV data were averaged to define a reference profile shape for use in determining the accuracy of the LARC surveys. The two systems were found to compare extremely well with a mean difference of $\sim 1 \mathrm{centimeter}(\mathrm{cm})$, well within measurement accuracy. The two systems compare best on the mildly sloping, shore-parallel shoreface, seaward of the nearshore sandbar where the two measuring systems differ least. The root mean square error between the LARC measurements and the CRAB mean profile was $2.2 \mathrm{~cm}$.

\section{SUBJECT TERMS}

Coastal engineering, Data collection platforms, Hydrographic surveying, Oceanographic instruments, Oceanography, Scientific apparatus and instruments

\begin{tabular}{|c|c|c|c|c|c|}
\hline \multicolumn{3}{|c|}{ 16. SECURITY CLASSIFICATION OF: } & \multirow{2}{*}{$\begin{array}{l}\text { 17. LIMITATION OF } \\
\text { ABSTRACT }\end{array}$} & \multirow{2}{*}{$\begin{array}{l}\text { 18. NUMBER OF } \\
\text { PAGES }\end{array}$} & \multirow{2}{*}{$\begin{array}{l}\text { 19a. NAME OF RESPONSIBLE PERSON } \\
\text { Michael Forte }\end{array}$} \\
\hline a. REPORT & b. ABSTRACT & c. THIS PAGE & & & \\
\hline Unclassified & Unclassified & Unclassified & SAR & 44 & $\begin{array}{l}\text { 19b. TELEPHONE NUMBER (Include area code) } \\
\text { 252-261-6840 }\end{array}$ \\
\hline
\end{tabular}

